\title{
A New Method to Diagnose Cyclone-Cyclone Interaction and Its Influences on Precipitation
}

\author{
ZuOHAO CAO \\ Environment and Climate Change Canada, Toronto, Ontario, Canada \\ QIN XU \\ NOAA/National Severe Storms Laboratory, Norman, Oklahoma \\ DA-LIN ZHANG \\ Department of Atmospheric and Oceanic Science, University of Maryland, College Park, College Park, Maryland
}

(Manuscript received 20 December 2018, in final form 9 May 2019)

\begin{abstract}
Unlike the classical point vortex model, a new method is developed to extract flows induced not only by vorticity but also by divergence in a well-defined vortex core area of a cyclone. This new method is applied to diagnosing the interactions of three midlatitude cyclones (called A, B, and C) that account for a missed summer severe rainfall forecast, in which the daily precipitation predicted by the Canadian operational model is an order of magnitude smaller than the rain gauge and radar measurements. In this event, cyclone B, responsible for the severe rainfall occurrence, was advected largely by flows induced by two neighboring cyclones: A and $\mathrm{C}$ to the west and east, respectively. This work attempts to assess whether and to what degree the vertical tilt of the observed cyclone versus that of the forecast cyclone $\mathrm{B}$ is caused by advections of the environmental flows (including A- and C-induced flows) at 500 and $1000 \mathrm{hPa}$. Results show that the observed cyclone B was advected mainly by the cyclone A-induced flow at $500 \mathrm{hPa}$ into a vertically tilted structure that was northwestward against the vertical shear of the environmental flow and thus favorable for upward motion and cyclone intensification around the time of severe rainfall. However, the forecast cyclone $\mathrm{B}$ was advected largely by the cyclone A-induced flow at $500 \mathrm{hPa}$ and the cyclone $\mathrm{C}$-induced flow at $1000 \mathrm{hPa}$ into an increasingly northward-tilted structure that was along the vertical shear of the environmental flow and thus unfavorable for upward motion and cyclone intensification, leading to the missed forecast of severe rainfall. Suggestions are made for future improvements of model forecasts.
\end{abstract}

\section{Introduction}

Precipitation has considerable impacts on our society and economy (e.g., Cao 2008; Cao and Ma 2009), but predicting it accurately in terms of its intensity, timing, and location is a challenge (Cao and Zhang 2004, 2016; Cao et al. 2004). The location error in predicting precipitation is vital since it can ruin our entire effort, no matter how accurate the predictions of the precipitation intensity and timing are. Cyclone-cyclone (e.g., two or multiple cyclone) interaction can be an important factor in determining cyclone tracks and associated precipitation (e.g., Cao and Zhang 2016). To date, we found only two publications in the literature on the interactions of two extratropical

\footnotetext{
Corresponding author: Zuohao Cao, zuohao.cao@canada.ca
}

continental cyclones (Ziv and Alpert 1995, 2003). In these studies, a point vortex model was applied to two neighboring cyclones to examine their interaction using analysis data, while a cyclone was treated in the same way as in the classical point vortex model [see Eq. (1) in section 3], that is, a point vortex inducing a purely rotational wind field. Based on our knowledge, so far there is no published work on three midlatitude continental cyclone interactions, especially their influences on precipitation forecasts.

This work is motivated by a missed summer severe rainfall (SSR) ${ }^{1}$ forecast: the Canadian operational Global

\footnotetext{
${ }^{1}$ As defined by the Ontario storm prediction center, an SSR event is considered when its rainfall rate exceeds $50 \mathrm{~mm} \mathrm{day}^{-1}$ or $75 \mathrm{~mm}$ in $48 \mathrm{~h}$ in Ontario.
} 

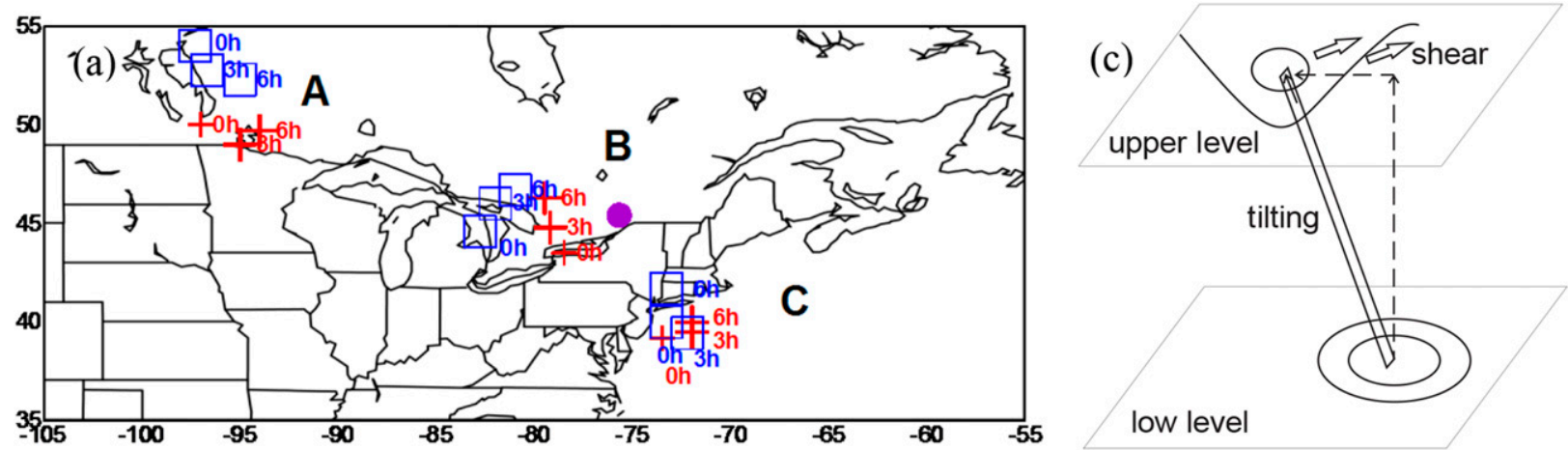

low level

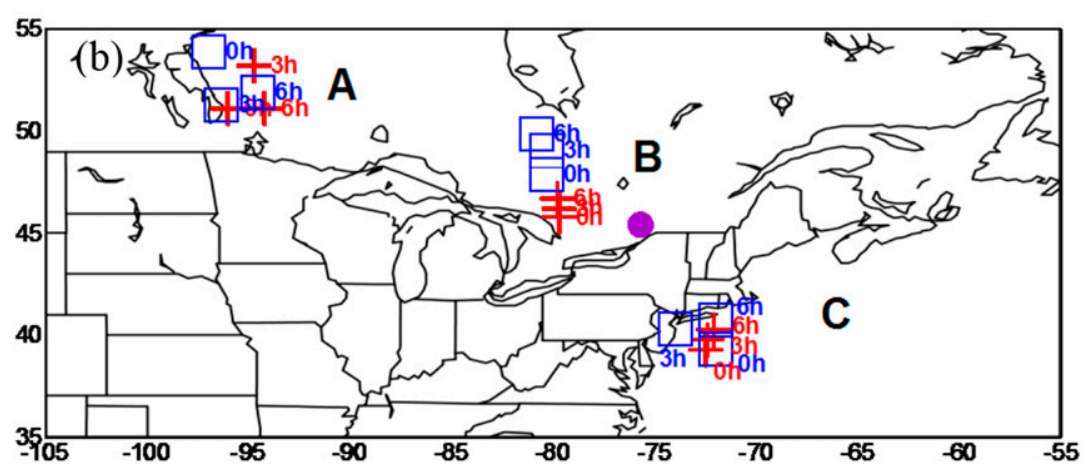

(d)

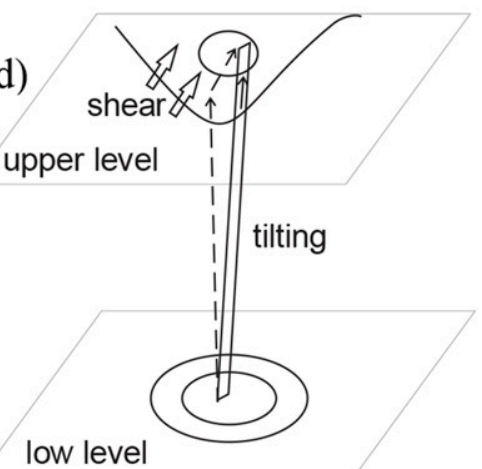

FIG. 1. Tracks of three cyclones (A, B, and C) at 1000 (denoted by red plus signs) and 500 (denoted by blue squares) hPa based on (a) the NARR and (b) the GEM regional model (0000 UTC run) forecasts at hours (UTC) labeled along the cyclone paths. A large dot indicates the location of Ottawa. Also shown are schematic diagrams for cyclone B of tilting (denoted by rectangle bars from low-level $1000 \mathrm{hPa}$ to upper-level $500 \mathrm{hPa}$ ) and wind shear between 500 and $1000 \mathrm{hPa}$ (denoted by big arrows) of (c) the NARR and (d) the GEM regional model. The solid lines represent geopotential heights at 1000 and $500 \mathrm{hPa}$, and dashed lines stand for components of tilting vectors.

Environmental Multiscale (GEM; Côté et al. 1998) regional model predicted daily precipitation of about $5 \mathrm{~mm}$ in Ottawa, Ontario, Canada, on 24 July 2009, whereas the rain gauge and the radar measurements were, respectively, 67.2 and $75-100 \mathrm{~mm}$ (Table 1 of Cao and Zhang 2016). The event involves interactions among three cyclones and their influences on the SSR over the Great Lakes region (Cao and Zhang 2016). This SSR event occurred in the Ottawa area and was associated with three extratropical cyclones labeled as $\mathrm{A}, \mathrm{B}$, and $\mathrm{C}$ in Fig. 1. Cyclone $\mathrm{B}$ was responsible for rainfall over the Ottawa area, mostly around 0300 UTC 24 July when severe rainfall occurred.

The observed [i.e., North American Regional Reanalysis (NARR); Mesinger et al. 2006] cyclone B tilted northwestward with height partially against the vertical shear of the environmental flow between 500 and $1000 \mathrm{hPa}$ (Fig. 1c). This resulted in positive vorticity advection by thermal wind of the environmental flow, which was conducive to upward motion (Sutcliffe 1947; Trenberth 1978) and favorable for cyclone B's intensification. Note also that the horizontal distance (about $350 \mathrm{~km}$ ) between the 500- and 1000 -hPa centers of observed cyclone B was well within the radius of Rossby deformation (i.e., $L_{R}=H N / f \approx 500 \mathrm{~km}$ for a scale height of $H=5 \mathrm{~km}$ between 500 and $1000 \mathrm{hPa}$ with BruntVäisälä frequency of $N \approx 10^{-2} \mathrm{~s}^{-1}$ and Coriolis frequency of $f \approx 10^{-4} \mathrm{~s}^{-1}$ ). Such an up-shear-tilted vortex structure could lead to cyclone B's intensification effectively through reinforced interactions between the upperlevel and lower-level potential vorticity (PV) anomalies (see section 6e and Fig. 21 of Hoskins et al. 1985).

The model-predicted cyclone B, however, was tilted northward with height largely along the vertical shear vector of the environmental flow between 500 and $1000 \mathrm{hPa}$ (Fig. 1d). This results in negative vorticity advection by thermal wind of the environmental flow, which was conducive to downward motion (Sutcliffe 1947; Trenberth 1978) and unfavorable for cyclone intensification, leading to a missed forecast of severe rainfall in Ottawa (Table 1 of Cao and Zhang 2016).

Here, the environmental flow (with respect to cyclone B) is defined as the total flow minus the flow induced by cyclone B. This environmental flow includes the flow induced by cyclones $\mathrm{A}$ and $\mathrm{C}$. This paper aims to examine whether or not and to what extent the vertical tilt 
of the observed (or forecast) cyclone B around 0300 UTC could be attributed to different movements of cyclone B caused by the different advections of the environmental flows at two different vertical levels (500 and $1000 \mathrm{hPa})$. Conventionally, $1000 \mathrm{hPa}$ is used to characterize cyclone positions and tracks, while $500 \mathrm{hPa}$ is somehow related to a steering level. Although no consensus has been reached on which level should be used as a steering level, it is generally accepted that the midtropospheric advections (at 700-500 $\mathrm{hPa}$ ) have the best correlation with cyclone movement (e.g., Chan et al. 1980; Chan and Gray 1982). Using the 12-yr composite analysis of tropical cyclone tracks, Chan et al. (1980) found that $500 \mathrm{hPa}$ was the best steering level.

To achieve the abovementioned goal, the flows induced by a cyclone have to be treated as realistically as possible by including both rotational and divergent (potential) flows induced by the vorticity and divergence over a well-defined vortex core area of the cyclone. Clearly, the classical point vortex model treating a cyclone as a point without including divergence-induced velocity, as described by Fujiwhara (1931), Lamb (1945), Batchelor (1980), and Aref (1983), is not suitable for the abovementioned purpose. To this end, a new diagnostic method is developed herein, as an improvement to the classical point vortex model, to evaluate cyclonecyclone interactions at two vertical levels. Here, the vorticity (or divergence) attributed to a cyclone is distributed in a finite area (i.e., a well-defined vortex core area) rather than concentrated at a point, and the cyclone-cyclone interaction refers to the influences of induced velocities by vorticity and divergence in the vortex core areas of a neighboring cyclone (A or C) on the target cyclone (B). In this method, the rotational and divergent flows induced by cyclones are computed by inverting the vorticity and divergence in their vortex core areas (without treating the cyclone crudely as a point vortex).

The next section describes the data used for this study. Section 3 provides a brief review of the classical point vortex model in connection with the triple cyclonecyclone interaction considered in this paper. Section 4 presents the new diagnostic method for cyclone-cyclone interactions. Section 5 shows diagnoses of the movements of cyclone B caused by the advections of the environmental flows (including those induced by cyclones A and C) at the two vertical levels using the NARR and the GEM, respectively. We will then discuss severe rainfall forecast errors, based on the diagnosed different movements and structures between the two datasets, and address the different vertical tilts of the observed and predicted cyclone $\mathrm{B}$ in determining large-scale forcing for the severe rainfall event. Discussions and conclusions will be given in the final section.

\section{Data}

The following datasets are used to carry out diagnoses of the cyclone-cyclone interactions: 1) the hourly operational GEM regional model (Côté et al. 1998) forecasts with a $15-\mathrm{km}$ horizontal resolution and 58 vertical levels, retrieved from the archive at the Canadian Meteorological Centre (CMC), 2) the 3-hourly NARR with a horizontal resolution of $32 \mathrm{~km}$ and 29 constant pressure levels that are archived at the National Centers for Environmental Prediction (NCEP) (Mesinger et al. 2006), 3) the daily rain gauge data plus a small number of the hourly rainfall data obtained from the National and/or Ontario Climate Center, 4) radar-estimated rainfall accumulation and rainfall rates at 10-min intervals obtained from the Canadian national radar network, covering areas mainly along the U.S.-Canada border, and 5) the observed soundings obtained from the University of Wyoming. Details can be found in Cao and Zhang (2016).

\section{Classical point vortex model and triple-cyclone interactions}

When two cyclones become close to each other, they tend to rotate cyclonically relative to each other. This phenomenon, called "binary cyclone," has been studied for a long time using the classical point vortex model (Fujiwhara 1931; Lamb 1945; Batchelor 1980; Aref 1983). In the classical point vortex model, a cyclone is treated as a point vortex induced by an infinitely intense vorticity at a single point $\mathbf{x}_{c}$ with the vorticity field formulated by $C \delta\left(\mathbf{x}-\mathbf{x}_{c}\right)$, where $\delta\left(\mathbf{x}-\mathbf{x}_{c}\right)$ denotes the delta function centered at point $\mathbf{x}_{c}$ in the twodimensional horizontal space of $\mathbf{x} \equiv(x, y)$ (e.g., a constant pressure surface) and $C$ is the point vortex intensity measured by its generated circulation. By definition, a cyclonic circulation is an integral of velocity along a closed circuit cyclonically around an area enclosed by the loop. According to the Green's theorem, this closed line integral is equal to the integrated vorticity over the area enclosed by the loop. Since $\delta\left(\mathbf{x}-\mathbf{x}_{c}\right)$ is zero everywhere except at the vortex center point $\mathbf{x}_{c}$ where $\delta\left(\mathbf{x}-\mathbf{x}_{c}\right)$ is infinitely large, the circulation generated by a point vortex is independent of the shape of the loop (as long as the loop encircles $\mathbf{x}_{c}$ ). The velocity field generated by such a point vortex is given by [see Eq. (7.3.13) of Batchelor 1980]

$$
\mathbf{v}(\mathbf{x})=(C / 2 \pi) \mathbf{k} \times\left(\mathbf{x}-\mathbf{x}_{c}\right) /\left|\mathbf{x}-\mathbf{x}_{c}\right|^{2},
$$

where $\mathbf{k}$ is the vertical unit vector.

In the classical point vortex model of binary cyclones, the two cyclones are represented by two point vortices with positive circulations $C_{1}$ and $C_{2}$, respectively. In this 
case, the first (or second) point vortex is advected by the velocity induced by the second (or first) point vortex. According to Eq. (1), the moving speed of the first (or second) vortex centered at $\mathbf{x}_{c 1}$ (or $\mathbf{x}_{c 2}$ ) is given by $V_{1}=$ $C_{2} /(2 \pi|\mathbf{r}|)\left[\right.$ or $\left.V_{2}=C_{1} /(2 \pi|\mathbf{r}|)\right]$ and the moving direction is perpendicular to $\mathbf{r} \equiv \mathbf{x}_{c 2}-\mathbf{x}_{c 1}$ and thus the first (or second) vortex rotates cyclonically with respect to $\mathbf{x}_{c 2}\left(\right.$ or $\left.\mathbf{x}_{c 1}\right)$. This implies that the two vortex centers rotate cyclonically relative to each other, their individual speed ratio obeys

$$
V_{1} / V_{2}=C_{2} / C_{1},
$$

and their relative rotation rate is given by [see Eq. (7.3.16) of Batchelor 1980]

$$
\omega=\left(C_{1}+C_{2}\right) /\left(2 \pi|\mathbf{r}|^{2}\right) .
$$

When the above classical point vortex model is applied to a binary-cyclone case at a given vertical level in the real atmosphere, the intensity of each point vortex measured by its generated circulation $C$ needs to be estimated by the integrated vorticity over a properly defined vortex core area around the center of the concerned cyclone. By applying this type of intensity estimation to the classical point vortex model, Ziv and Alpert (1995) found that midlatitude binary cyclones with the separation distance ranging from 1400 to $1800 \mathrm{~km}$ often rotated around each other cyclonically at a rate proportional to their combined intensities.

For triple extratropical cyclone-cyclone interactions considered in our case, cyclone B is the target cyclone located near Ottawa where the SSR occurred. We will pay particular attention to the interactions between cyclones $\mathrm{B}$ and $\mathrm{A}$ (referred to as $\mathrm{A}-\mathrm{B}$ ), and between cyclones $\mathrm{B}$ and $\mathrm{C}$ (referred to as $\mathrm{B}-\mathrm{C}$ ). The interaction between cyclones $\mathrm{A}$ and $\mathrm{C}$ is assumed to be negligible since the distance between two cyclones is beyond the critical separation distance of $1400-1800 \mathrm{~km}$ (Ziv and Alpert 1995).

\section{New diagnostic method}

The classical point vortex model reviewed in section 3 has the following major limitations: 1 ) The point vortexinduced flow becomes singular [with unbounded increase of velocity, as shown in Eq. (1)] toward the vortex center, so the induced flow cannot be realistically diagnosed in and around the vortex core of the cyclone. 2) The point vortex-induced flow is purely rotational, but the flow field induced by a cyclone not only has a rotational component but also contains a divergent component. 3) Because the point vortex model does not consider any divergent flow, it cannot be used to realistically compute or diagnose the environmental flow for the target cyclone.
To overcome the above limitations, a new diagnostic method is introduced here to consider both the rotational and divergent parts of the flow induced by a cyclone. In the two-dimensional space of $\mathbf{x}$ on a constant pressure surface, the vorticity-induced rotational velocity, denoted by $\mathbf{v}_{r} \equiv\left(u_{r}, v_{r}\right)$, can be expressed by

$$
\mathbf{v}_{r}=\mathbf{k} \times \nabla \psi,
$$

where $\psi$ is the streamfunction, $\nabla \equiv\left(\partial_{x}, \partial_{y}\right)$ is the horizontal gradient operator, and $\mathbf{k} \times \nabla=\left(-\partial_{y}, \partial_{x}\right)$ is the horizontal gradient operator rotated counterclockwise by $90^{\circ}$. The streamfunction in the unbounded domain of $\mathbf{x}$ induced by the vorticity $\zeta$ field within a cyclone vortex core area can be solved from Eq. (3.1b) of $\mathrm{Xu}$ et al. (2011); that is,

$$
\psi(\mathbf{x})=(2 \pi)^{-1} \int_{s} d \mathbf{x}^{\prime} \zeta\left(\mathbf{x}^{\prime}\right) \ln \left|\mathbf{x}^{\prime}-\mathbf{x}\right|,
$$

where $\int_{s} d \mathbf{x}^{\prime}$ denotes the integration over the vortex core area $S$. Substituting Eq. (5) into Eq. (4) gives the induced rotational velocity field in the following form:

$$
\mathbf{v}(\mathbf{x})=(2 \pi)^{-1} \int_{s} d \mathbf{x}^{\prime} \zeta\left(\mathbf{x}^{\prime}\right) \mathbf{k} \times\left(\mathbf{x}-\mathbf{x}^{\prime}\right) /\left|\mathbf{x}-\mathbf{x}^{\prime}\right|^{2},
$$

where $\nabla \ln \left|\mathbf{x}^{\prime}-\mathbf{x}\right|=\left(\mathbf{x}-\mathbf{x}^{\prime}\right) /\left|\mathbf{x}-\mathbf{x}^{\prime}\right|^{2}$ is used. Note that $\left(\mathbf{x}-\mathbf{x}^{\prime}\right) /\left|\mathbf{x}-\mathbf{x}^{\prime}\right|^{2}$ on the right-hand side of Eq. (6) becomes singular as $\mathbf{x}^{\prime}=\mathbf{x}$ but it is still integrable in $\mathbf{x}^{\prime}$, and the integral can be computed using the gridstaggering discretization scheme (with no singularity involved) that is similar to that in Eq. (2.1b) of Cao and $\mathrm{Xu}$ (2011).

Similarly, the divergence-induced velocity, denoted by $\mathbf{v}_{d} \equiv\left(u_{d}, v_{d}\right)$, can be expressed by

$$
\mathbf{v}_{d}=\nabla \chi,
$$

where $\chi$ is the velocity potential. The velocity potential in the unbounded domain of $\mathbf{x}$ induced by the divergence $\alpha$ within a cyclone core area can be solved from Eq. (3.1a) of Xu et al. (2011); that is,

$$
\chi(\mathbf{x})=(2 \pi)^{-1} \int_{s} d \mathbf{x}^{\prime} \alpha\left(\mathbf{x}^{\prime}\right) \ln \left|\mathbf{x}^{\prime}-\mathbf{x}\right|,
$$

where now $\int_{s} d \mathbf{x}^{\prime}$ denotes the integration over the cyclone area $S$. Substituting Eq. (8) into Eq. (7) gives the induced divergent velocity field in the following form:

$$
\mathbf{v}_{d}(\mathbf{x})=(2 \pi)^{-1} \int_{s} d \mathbf{x}^{\prime} \alpha\left(\mathbf{x}^{\prime}\right)\left(\mathbf{x}-\mathbf{x}^{\prime}\right) /\left|\mathbf{x}-\mathbf{x}^{\prime}\right|^{2}
$$


The integral on the right-hand side of Eq. (9) is computed using the grid-staggering discretization scheme similar to that in Eq. (2.1a) of Cao and Xu (2011).

For a point vortex centered at $\mathbf{x}=\mathbf{x}_{c}$, we have $\zeta(\mathbf{x})=$ $C \delta\left(\mathbf{x}-\mathbf{x}_{c}\right)$. Substituting $\zeta(\mathbf{x})=C \delta\left(\mathbf{x}-\mathbf{x}_{o}\right)$ into Eq. (6) recovers Eq. (1). Thus, Eq. (6) represents a realistic extension of the classical point vortex model in Eq. (1) and it reduces to the classical one as the target cyclone is idealized into a point vortex. In addition, our new diagnostic method computes the flows induced by a cyclone more realistically by inverting not only the vorticity but also the divergence in a well-defined vortex core area of the cyclone. Here, the vortex core area is defined as an area enclosed by the outmost closed isobar or isogeopotential height, which could be as large as about $500 \mathrm{~km}$ in radius (e.g., see Fig. 3b). This closed isobar criterion is suitable for lower levels such as $1000 \mathrm{hPa}$. However, at upper levels such as the $500-\mathrm{hPa}$ the environmental flow becomes prevailing, so the geopotential height associated with the total flow (that combines the environmental flow with the flow induced by a concerned cyclone) forms a trough (instead of an isolated low) around the center of the concerned cyclone. In this situation, the maximum relative vorticity can be used to determine the cyclone center at $500 \mathrm{hPa}$. Then, the horizontal displacement between the 500- and $1000-\mathrm{hPa}$ cyclone centers can be used to project the vortex core area from 1000 to $500 \mathrm{hPa}$ (see Fig. 2).

When the new diagnostic method is applied to the triple extratropical cyclone-cyclone interactions considered in this paper, the environmental flow that advects the target cyclone $\mathrm{B}$ is computed by subtracting the target cyclone-induced flow from the total flow. This environmental flow contains the flows induced by cyclones $\mathrm{A}$ and $\mathrm{C}$, so it can be partitioned into the following components: 1) the flow induced by cyclone A, 2) the flow induced by cyclone $\mathrm{C}$, and 3 ) the residual environmental flow (computed by subtracting the two cyclone-induced flows from the environmental flow). In the next section, a total environmental flow and its partitioned component flows will be computed based on the two datasets (NARR and GEM), and they are then used to diagnose how and to what extent the environmental flow advection and its partitioned component flow advections contribute to the movement of the target cyclone B at each vertical level $(1000$ or $500 \mathrm{hPa})$ from 0000 to 0300 UTC 24 July. The results obtained from NARR data will be used as a benchmark to examine how the environmental flow and its partitioned component flows advect the target cyclone $\mathrm{B}$ in the GEM differently from those in NARR, and how and to what extent these differences lead to the missed forecast of severe rainfall in GEM.

\section{Results}

As shown in Fig. 1, the GEM-model-forecast locations of cyclone B at 1000 and $500 \mathrm{hPa}$ at 0300 UTC are about $160 \mathrm{~km}$ northwest and $370 \mathrm{~km}$ northeast, respectively, of the NARR-analyzed locations (cf. Figs. 1a,b). These location errors of cyclone B in GEM appear to be the major causes of errors in the forecast meteorological variables and their gradients in Ottawa on the east side of the target cyclone B. As shown in Table 1, at 0300 UTC the model-predicted vertical gradients of temperature $\left(5^{\circ} \mathrm{C}\right)$ and specific humidity $\left(2.1 \mathrm{~g} \mathrm{~kg}^{-1}\right)$ in the lowest 150 -hPa layer are much smaller than the NARR-analyzed gradients $\left(8^{\circ} \mathrm{C}\right.$ and $4.7 \mathrm{~g} \mathrm{~kg}^{-1}$, respectively). The model-predicted CAPE is only $148.8 \mathrm{~J} \mathrm{~kg}^{-1}$ in Ottawa, whereas the NARR-analyzed CAPE is $690.5 \mathrm{~J} \mathrm{~kg}^{-1}$ (Table 1). Insufficient model CAPE for the parameterized deep convection leads to less moisture transported upward for condensation at upper levels, less conversion of water vapor into cloud water at upper levels, and less precipitation for the SSR event thereby (daily rainfall is about $5 \mathrm{~mm}$ in the GEM model vs daily rain gauge observation of $67.2 \mathrm{~mm}$ and radar measurement of $75-100 \mathrm{~mm}$ in Ottawa; see Cao and Zhang 2016). Furthermore, the NARR-analyzed vertical motion on $700 \mathrm{hPa}$ is about $-0.6 \mathrm{~Pa} \mathrm{~s}^{-1}$ in Ottawa, whereas the model-predicted vertical motion is around $0.2 \mathrm{~Pa} \mathrm{~s}^{-1}$ (Table 1). The opposite sign between the NARR-analyzed and the model-predicted vertical motion indicates that the model-predicted downward motion inhibits the triggering of the parameterized convection and condensation in Ottawa but it is enhanced by the NARR-analyzed strong upward motion.

Table 2 exhibits comparisons between the NARRanalyzed and the GEM-regional-model-forecast 1000-hPa cyclone $\mathrm{B}$ intensity measured by its generated circulation along the outmost closed isogeopotential height. At 0000 and 0300 UTC 24 July 2009, the model-predicted cyclone B intensity is, respectively, $2.9 \times 10^{6}$ and $2.3 \times$ $10^{6} \mathrm{~m}^{2} \mathrm{~s}^{-1}$, whereas the NARR-analyzed intensity is $9.7 \times 10^{6}$ and $9.5 \times 10^{6} \mathrm{~m}^{2} \mathrm{~s}^{-1}$. This result indicates that the model-predicted 1000 -hPa cyclone B is weaker than that in the NARR analysis.

\section{a. Diagnoses of cyclone-induced flows and their interactions in NARR}

Figure 3a shows the NARR-analyzed wind field at $1000 \mathrm{hPa}$ at $0000 \mathrm{UTC} 24 \mathrm{July}$. The rotational (in green) and divergent (in purple) flows induced by the target cyclone B at $1000 \mathrm{hPa}$ are inverted from the NARRanalyzed relative vorticity and divergence fields, respectively (Fig. 3b). As shown in Fig. 3b, the cyclone $\mathrm{B}$-induced rotational flow is dominant over its induced 


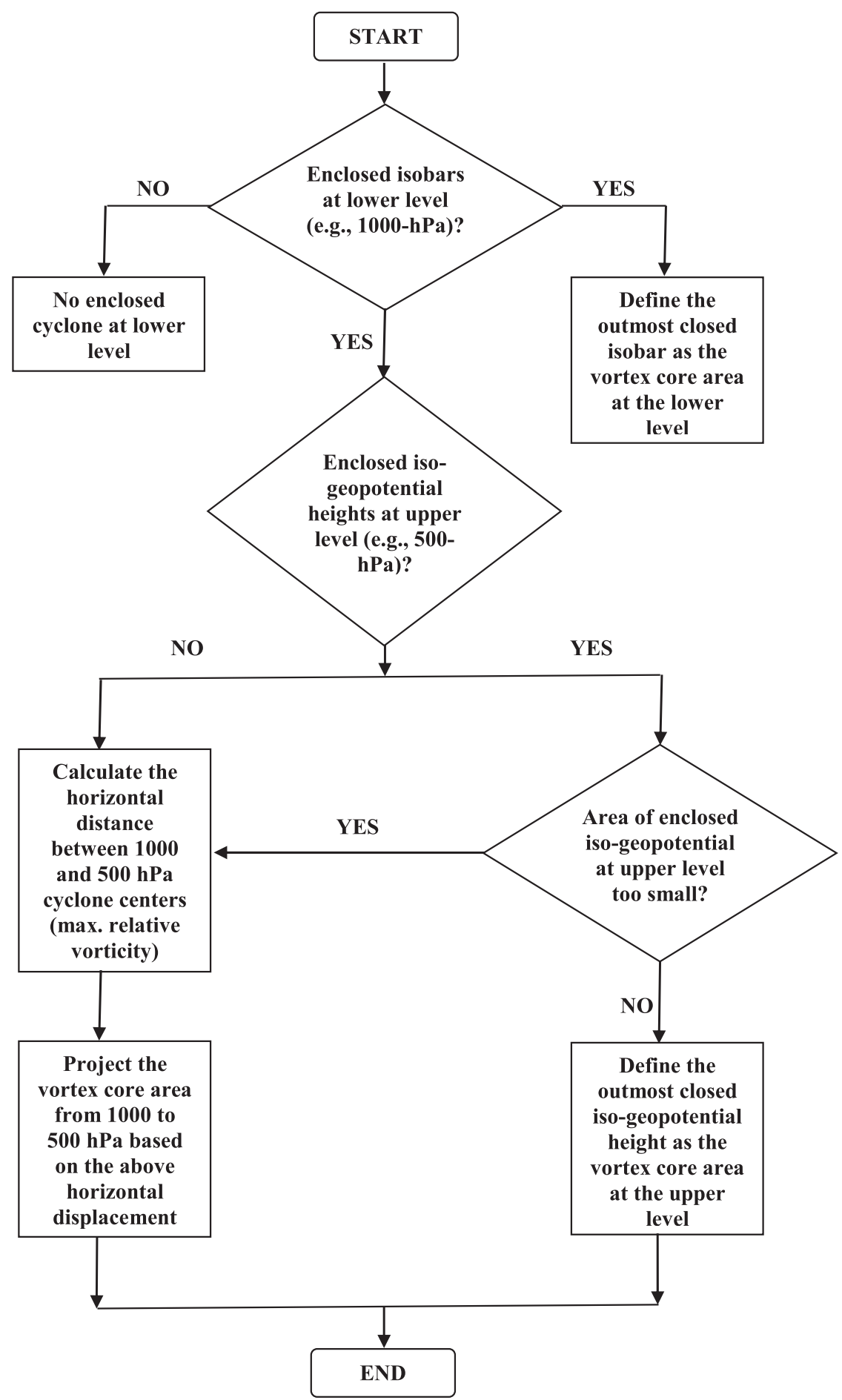

FIG. 2. A flowchart for defining vortex core areas at upper and lower levels.

divergent flow, and the latter diminishes more rapidly away from its vortex core (indicated by the yellow contour loop) than the former. Clearly, the divergent flow induced by cyclone B is significant and cannot be neglected in and around its own vortex (Fig. 3b). In particular, the cyclone B-induced divergent (in purple) flow generates convergence zones radiated outward from the center of cyclone B, while the cyclone B-induced rotational (in green) flow generates a strong cyclonic circulation around its center. Similarly, the cyclone 
TABLE 1. Comparison between the NARR analysis and the GEM regional model forecast at 0300 UTC 24 Jul 2009 in Ottawa $\left(45.42^{\circ} \mathrm{N}, 75.70^{\circ} \mathrm{W}\right)$.

\begin{tabular}{lcccr}
\hline \hline \multicolumn{1}{c}{ Data source } & $\Delta T$ in $1000-850 \mathrm{hPa}\left({ }^{\circ} \mathrm{C}\right)$ & $\Delta q$ in $1000-850 \mathrm{hPa}\left(\mathrm{g} \mathrm{kg}^{-1}\right)$ & $\mathrm{CAPE}\left(\mathrm{J} \mathrm{kg}^{-1}\right)$ & $700-\mathrm{hPa}$ omega $\left(\mathrm{Pa} \mathrm{s}{ }^{-1}\right)$ \\
\hline NARR analysis & 8 & 4.7 & 690.5 & -0.6 \\
GEM regional model & 5 & 2.1 & 148.8 & 0.2 \\
\hline
\end{tabular}

$\mathrm{C}$-induced rotational flow is stronger than its induced divergent flow (Fig. 3e), but the A-induced rotational flow is about the same intensity and coverage as its induced divergent flow (Fig. 3d).

Figure $3 \mathrm{c}$ presents the $1000-\mathrm{hPa}$ environmental flow computed by subtracting the B-induced flows of Fig. $3 \mathrm{~b}$ from the total flow of Fig. 3a. As seen in Fig. 3c, the environmental flow is about $5 \mathrm{~m} \mathrm{~s}^{-1}$ northwestward at and around the center of cyclone $\mathrm{B}$, and its resulting advection is consistent with and can largely explain the northwestward movement (about $100 \mathrm{~km}$ ) of the 1000-hPa cyclone B from 0000 to 0300 UTC (denoted by red plus signs in Fig. 1a).

As shown in Fig. 3b, at 0000 UTC 24 July, the cyclone $\mathrm{B}$-induced divergent and rotational flows at $1000 \mathrm{hPa}$ in the NARR are about $2.8 \mathrm{~m} \mathrm{~s}^{-1}$ northwestward and $1.5 \mathrm{~m} \mathrm{~s}^{-1}$ northwestward, respectively, at the center of cyclone B. Adding the environmental flow $\left(5 \mathrm{~m} \mathrm{~s}^{-1}\right.$ northwestward) with cyclone B-induced divergent $\left(2.8 \mathrm{~m} \mathrm{~s}^{-1}\right.$ northwestward) and rotational $\left(1.5 \mathrm{~m} \mathrm{~s}^{-1}\right.$ northwestward) flows, we have $9 \mathrm{~m} \mathrm{~s}^{-1}$ northwestward at and around the center of cyclone $\mathrm{B}$. This gives an estimated distance of about $100 \mathrm{~km}$ that cyclone B propagates from 0000 to 0300 UTC, which is the same distance cyclone $\mathrm{B}$ at $1000 \mathrm{hPa}$ travels during this period.

As explained in section 4, the environmental flow in Fig. $3 c$ contains three components: the first two components are the flows induced by cyclones $\mathrm{A}$ and $\mathrm{C}$, and the third component is the residual environmental flow, that is, the environmental flow minus the cyclones A and $\mathrm{C}$-induced flows. As shown in Fig. 3d, at and around the center of cyclone $\mathrm{B}$ at $1000 \mathrm{hPa}$, cyclone A-induced flow is about $1 \mathrm{~m} \mathrm{~s}^{-1}$ northwestward while cyclone $\mathrm{C}$-induced flow is about $1.5 \mathrm{~m} \mathrm{~s}^{-1}$ southwestward (Fig. 3e). As a result, both $\mathrm{A}$ - and $\mathrm{C}$-induced velocities at and around the center of cyclone $\mathrm{B}$ have westward components with a small magnitude $\left(<1 \mathrm{~m} \mathrm{~s}^{-1}\right)$, so their combination has little net effect on the movement of cyclone B (Fig. 3f). This indicates that the residual environmental flow (about 4-5 $\mathrm{m} \mathrm{s}^{-1}$ northwestward at and around the center of cyclone B) plays an important role in contributing to advecting the cyclone $\mathrm{B}$ at $1000 \mathrm{hPa}$ (Fig. 3f).

Figures $4 \mathrm{a}$ displays the $1000-\mathrm{hPa}$ NARR-analyzed wind field at 0300 UTC 24 July. Again, the B-induced rotational flow is dominant over its induced divergent flow (Fig. 4b). At this time, the divergent flows induced by cyclones $\mathrm{A}$ and $\mathrm{C}$ become stronger than those at 0000 UTC (cf. Figs. 3d,e and 4d,e). At 0300 UTC, the $1000-\mathrm{hPa}$ environmental flow is northwestward at and around the center of cyclone B (Fig. 4c) and still plays an important role in facilitating the northwestward movements of cyclone $\mathrm{B}$ at $1000 \mathrm{hPa}$, whereas the cyclone $\mathrm{A}-$ and $\mathrm{C}-$-induced rotational and divergent flows are largely canceled out (Figs. 4d,e) resulting in a small difference at and around the center of cyclone $\mathrm{B}$ at $1000 \mathrm{hPa}$ (about $1 \mathrm{~m} \mathrm{~s}^{-1}$; Fig. 4f).

The 500-hPa NARR-analyzed wind field at 0000 UTC 24 July, presented in Fig. 5a, shows a well-defined trough associated with cyclone $\mathrm{B}$, but weak disturbances with cyclones $\mathrm{A}$ and $\mathrm{C}$. The cyclone $\mathrm{B}$-induced rotational flow is dominant over its induced divergent flow at $500 \mathrm{hPa}$, as can be expected for the near-geostrophicbalanced flow state above the planetary boundary layer (Fig. 5b). The divergent flows induced by $500-\mathrm{hPa}$ cyclone B become virtually zero near its center. Similarly, the above features are observed for the cyclones A and $\mathrm{C}$-induced rotational and divergent flows (Figs. 5d,e).

The 500-hPa environmental flow, as shown in Fig. 5c, is about $8 \mathrm{~m} \mathrm{~s}^{-1}$ northeastward at and around the center of cyclone $\mathrm{B}$, and its advection is consistent with and can largely explain the northeastward movement (about $160 \mathrm{~km}$ ) of the $500-\mathrm{hPa}$ cyclone B from 0000 to 0300 UTC (denoted by blue squares in Fig. 1a).

At and around the center of cyclone $\mathrm{B}$ at $500 \mathrm{hPa}$, the cyclone A-induced stronger rotational flow is northeastward (Fig. 5d), while the cyclone C-induced weaker rotational flow is southwestward (Fig. 5e), indicating that the cyclone A-induced flows play a dominant role in advecting cyclone $\mathrm{B}$ at $500 \mathrm{hPa}$. The resulting flows induced by cyclones $\mathrm{A}$ and $\mathrm{C}$ at and around the center of cyclone $\mathrm{B}$ at $500 \mathrm{hPa}$ is about $5 \mathrm{~m} \mathrm{~s}^{-1}$ northeastward (Fig. 5f), which makes more than $63 \%$ contribution to the environmental flow in advecting cyclone $\mathrm{B}$ at $500 \mathrm{hPa}$.

TABLE 2. Comparison of 1000-hPa intensity $\left(10^{6} \mathrm{~m}^{2} \mathrm{~s}^{-1}\right)$ of cyclone $\mathrm{B}$ measured by its generated circulation along the outermost closed isogeopotential height between the NARR analysis and the GEM regional model forecast on 24 Jul 2009.

\begin{tabular}{lcc}
\hline \hline \multicolumn{1}{c}{ Time } & 0000 UTC & 0300 UTC \\
\hline NARR analysis & 9.7 & 9.5 \\
GEM regional model & 2.9 & 2.3 \\
\hline
\end{tabular}




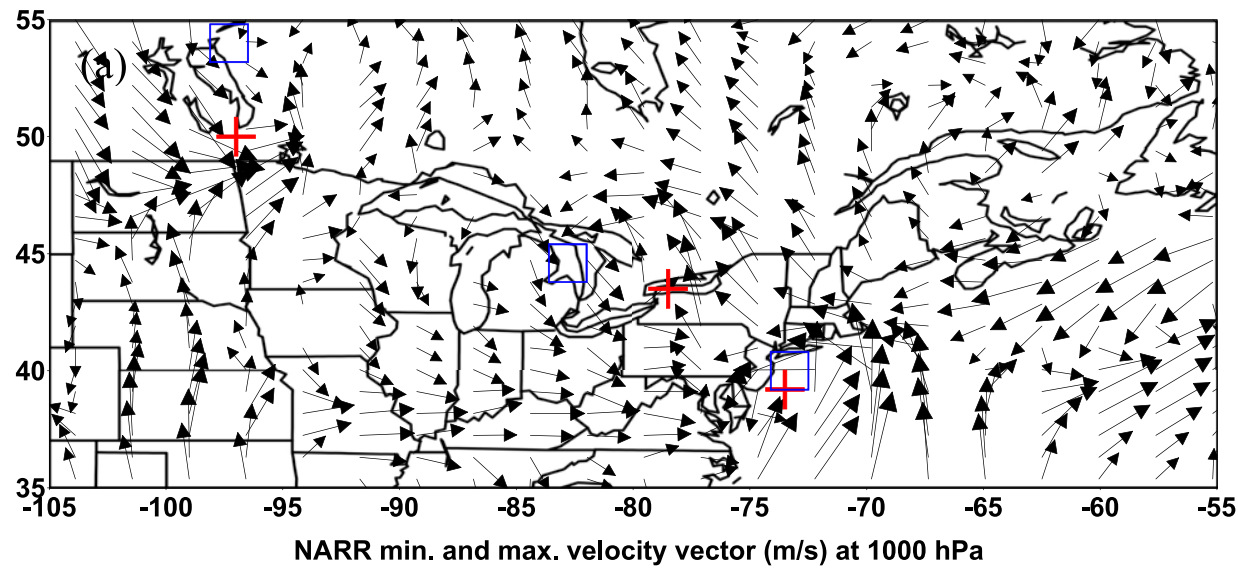

$\overrightarrow{1.0} \underset{13.0}{\longrightarrow}$

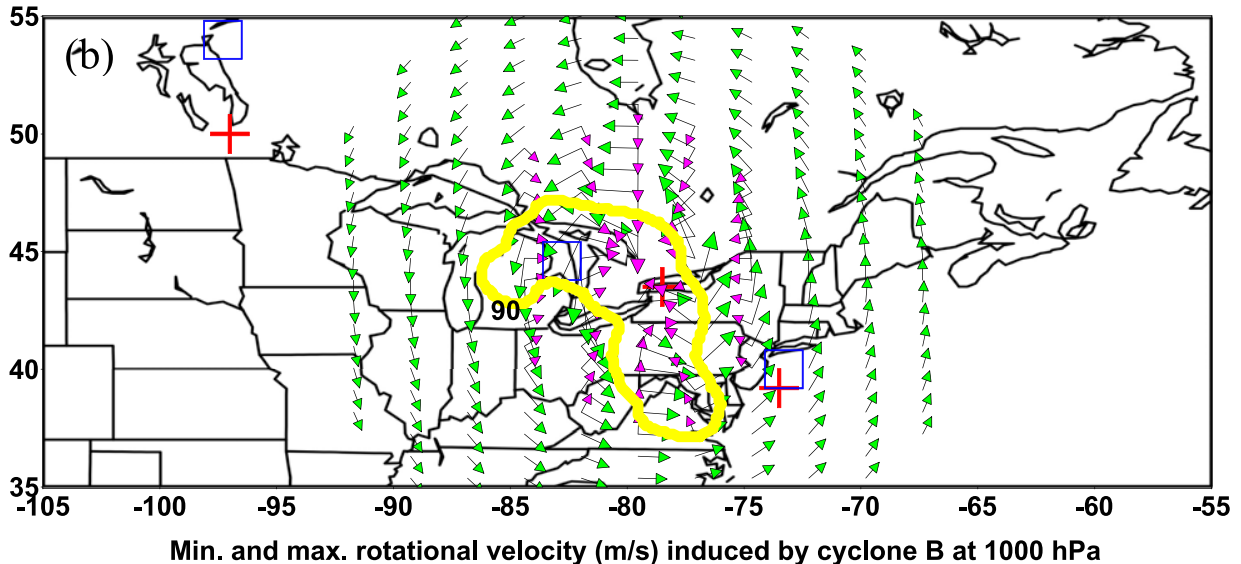

$$
\overrightarrow{1.0} 7.0
$$

Min. and max. divergent velocity $(\mathrm{m} / \mathrm{s})$ induced by cyclone $\mathrm{B}$ at $1000 \mathrm{hPa}$

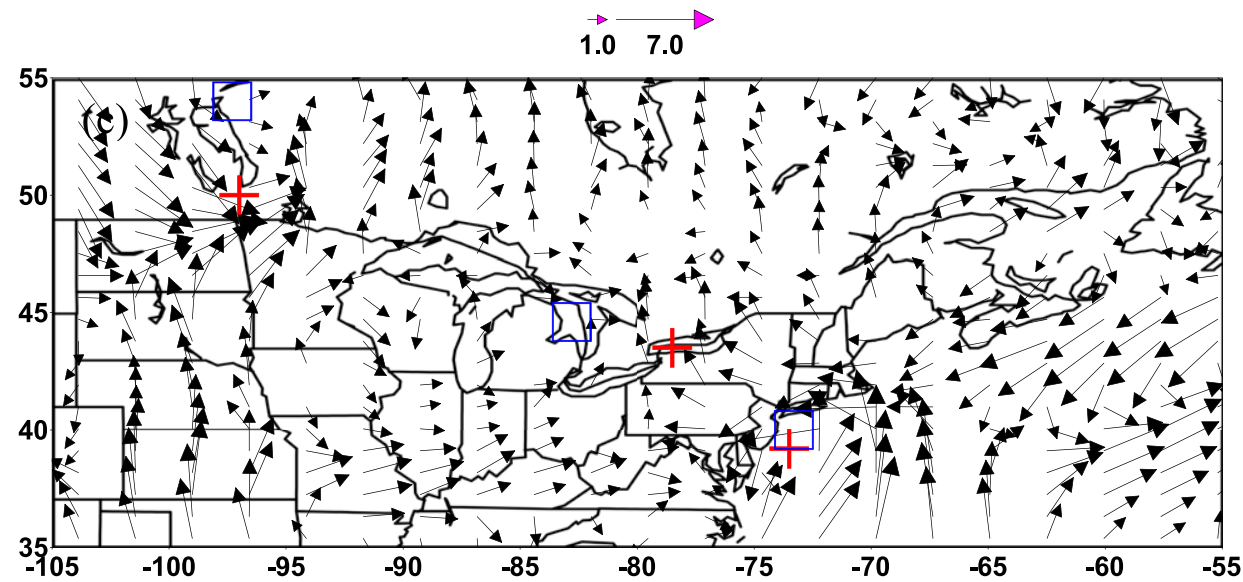

Difference between NARR total and cyclone B induced rotational and divergent velocity at $1000 \mathrm{hPa}$

$$
\overrightarrow{1.0} \underset{13.0}{\longrightarrow}
$$

FIG. 3. (a) NARR-analyzed horizontal velocity vectors $\left(\mathrm{m} \mathrm{s}^{-1}\right)$, (b) cyclone B-induced rotational flow $\left(\mathrm{m} \mathrm{s}^{-1}\right.$; green) and divergent flow $\left(\mathrm{m} \mathrm{s}^{-1}\right.$; purple), (c) environmental flow $\left[\mathrm{m} \mathrm{s}^{-1}\right.$; (a) minus (b)], (d) cyclone Ainduced rotational flow $\left(\mathrm{m} \mathrm{s}^{-1}\right.$; green) and divergent flow $\left(\mathrm{m} \mathrm{s}^{-1}\right.$; purple), (e) cyclone $\mathrm{C}$-induced rotational flow $\left(\mathrm{m} \mathrm{s}^{-1}\right.$; green) and divergent flow $\left(\mathrm{m} \mathrm{s}^{-1}\right.$; purple), and (f) residual environmental flow $\left[\mathrm{m} \mathrm{s}^{-1}\right.$; (c) minus (d) and (e)] at $1000 \mathrm{hPa}$ at $0000 \mathrm{UTC} 24 \mathrm{Jul} 2009$. Plus signs and squares respectively denote the geographic locations for centers of 1000- and 500-hPa cyclones A, B, and C, from left to right. A yellow contour indicates the vortex core area of 1000-hPa cyclone B enclosed by the outermost loop of closed isogeopotential height of $90 \mathrm{~m}$. 


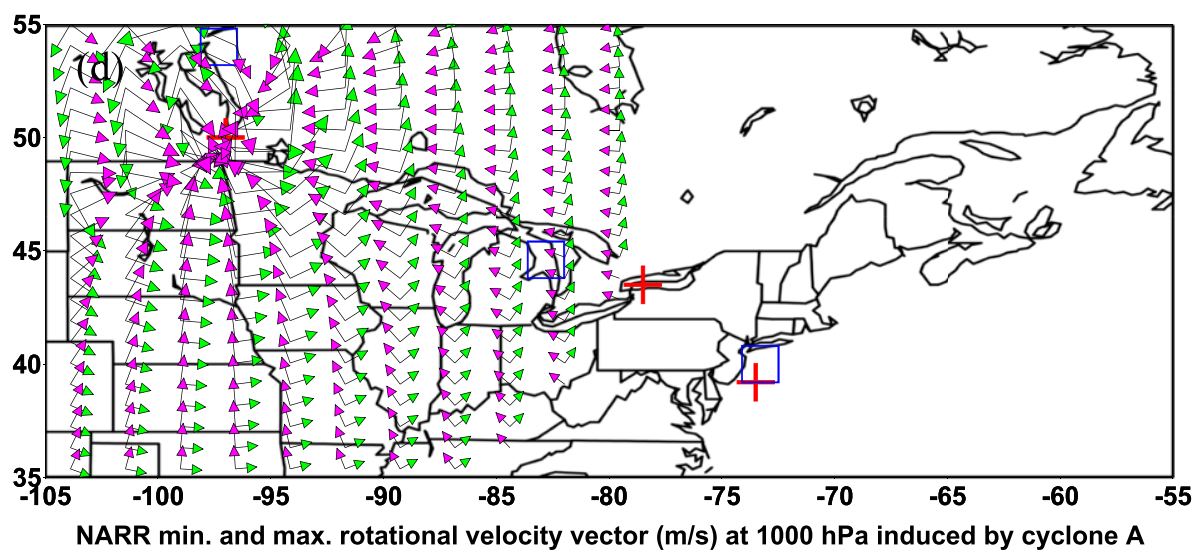

$$
\overrightarrow{1.0} 6.7
$$

NARR min. and max. divergent velocity vector $(\mathrm{m} / \mathrm{s})$ at $1000 \mathrm{hPa}$ induced by cyclone A

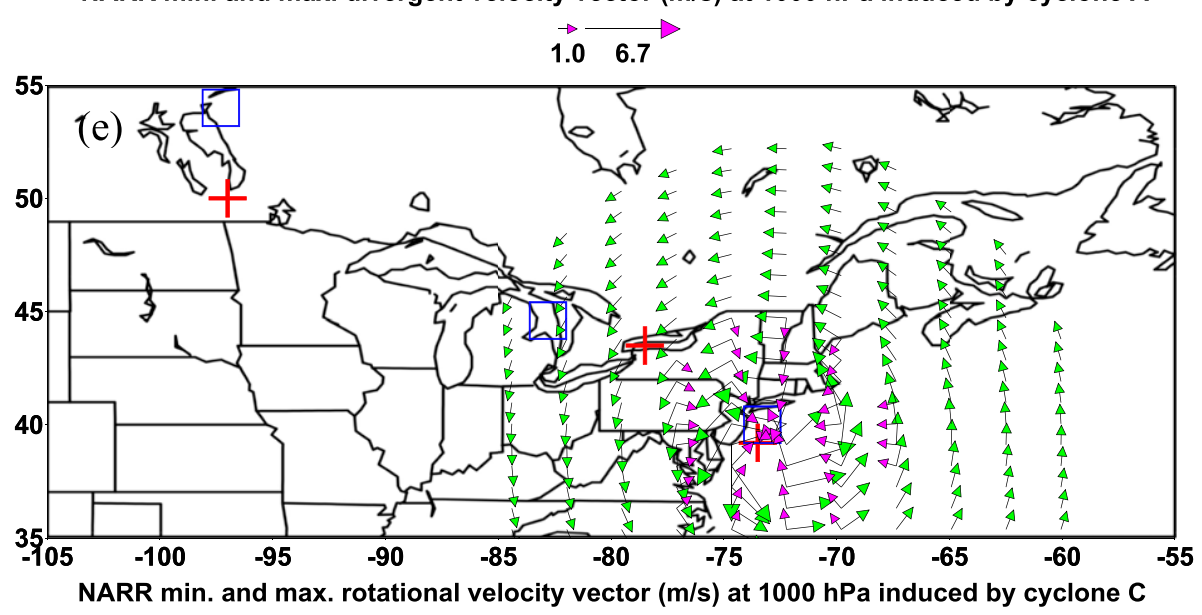

$$
\overrightarrow{1.0} \underset{9.6}{\longrightarrow}
$$

NARR min. and max. divergent velocity vector $(\mathrm{m} / \mathrm{s})$ at $1000 \mathrm{hPa}$ induced by cyclone $\mathrm{C}$

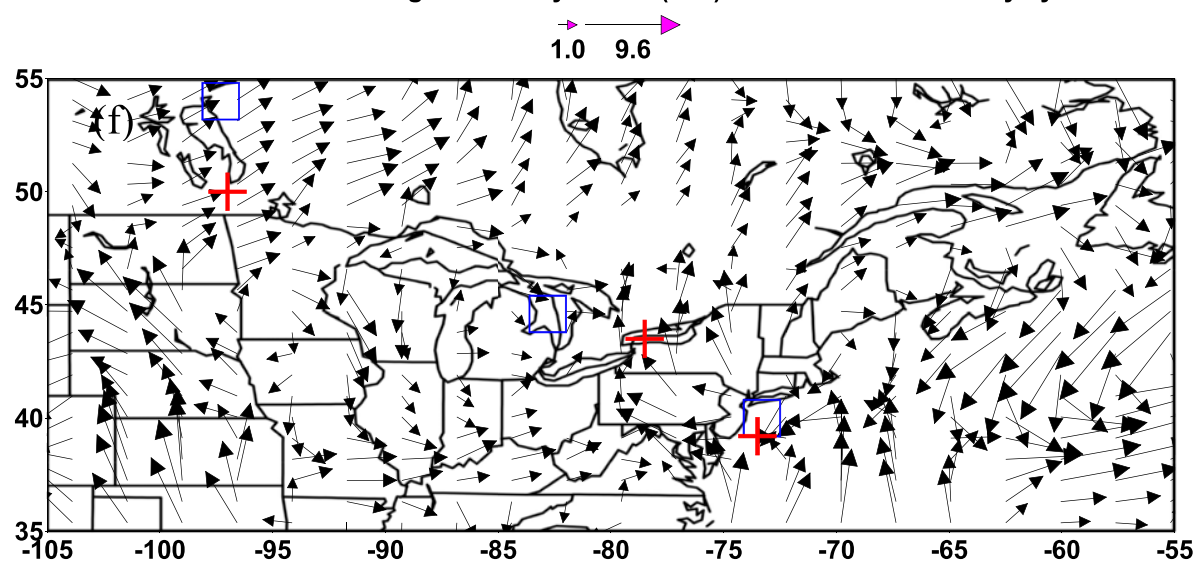

Difference between NARR total and cyclone A, B, C induced rotational and potential velocities $(\mathrm{m} / \mathrm{s})$ at 1000-hPa

$$
\overrightarrow{1.0} \underset{9.7}{\longrightarrow}
$$

FIG. 3. (Continued) 


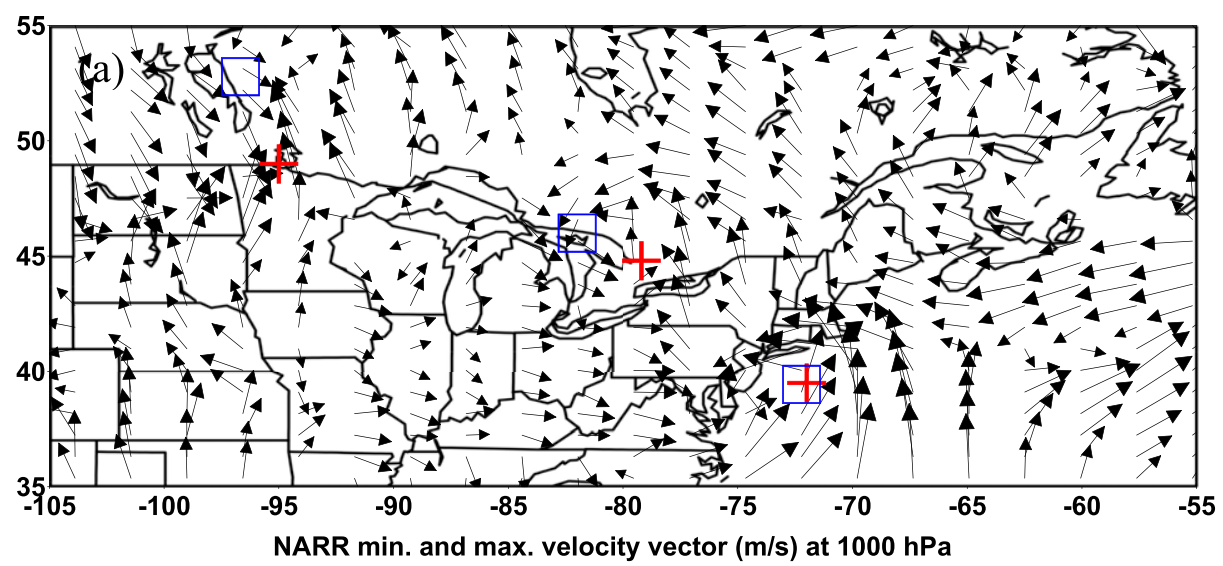

$\overrightarrow{1.0} \underset{15.0}{\longrightarrow}$

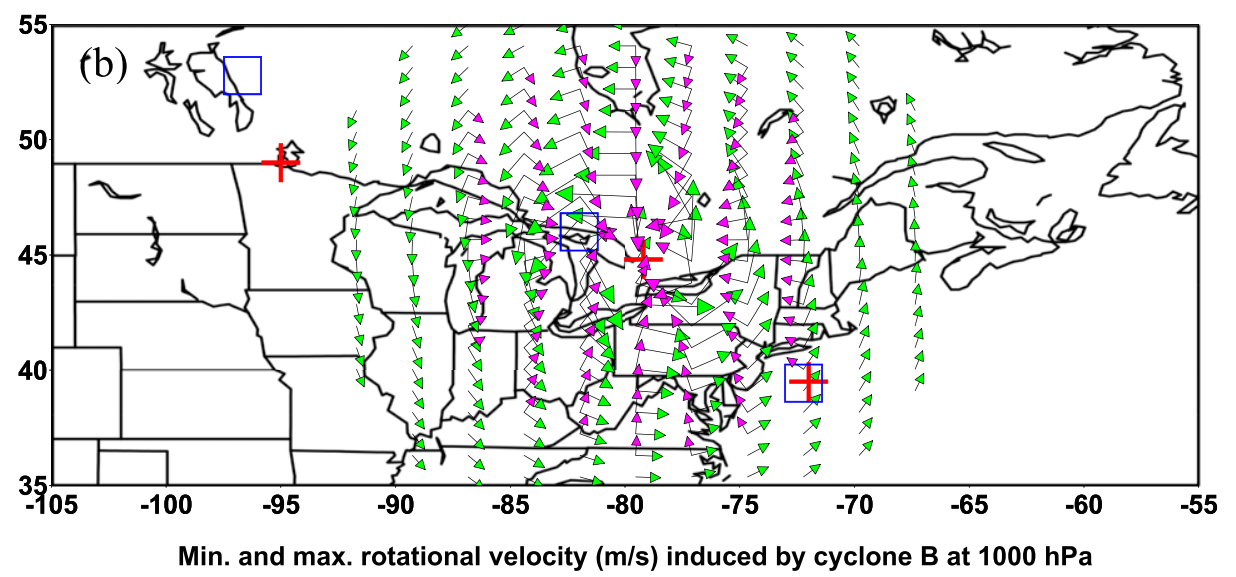

$$
\rightarrow \overrightarrow{1.0} 6.2
$$

Min. and max. divergent velocity $(\mathrm{m} / \mathrm{s})$ induced by cyclone $B$ at $1000 \mathrm{hPa}$

$$
\overrightarrow{1.0} 6.2
$$

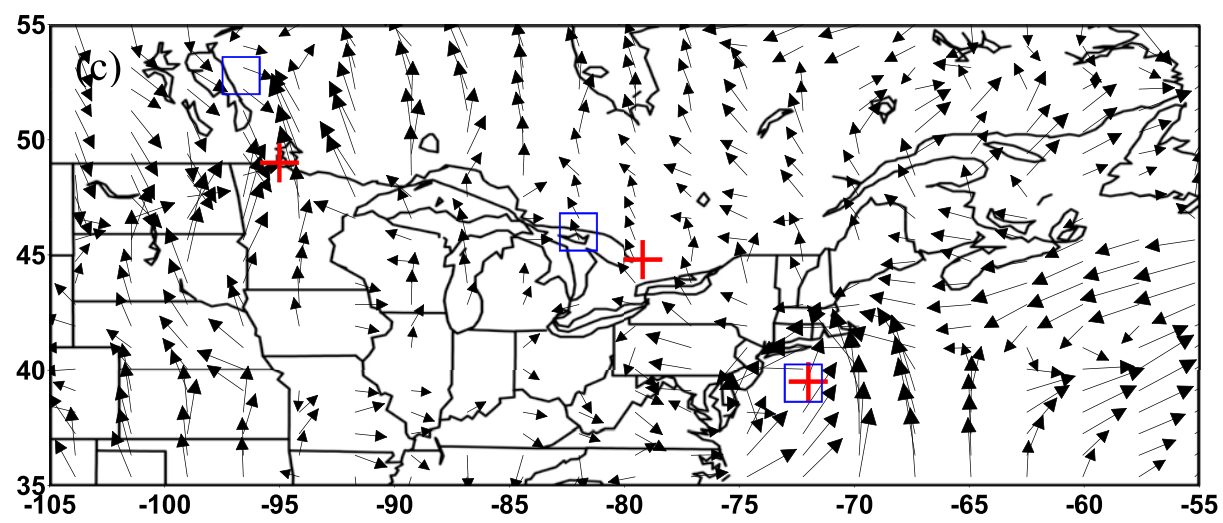

Difference between NARR total and cyclone B induced rotational and divergent velocity at $1000 \mathrm{hPa}$

$$
\overrightarrow{1.0} \underset{15.0}{\longrightarrow}
$$

FIG. 4. As in Fig. 3, but at 0300 UTC 24 Jul 2009 and now showing (f) both cyclones A and C-induced flow $\left[\mathrm{m} \mathrm{s}^{-1} ;\right.$ (d) plus (e)]. 


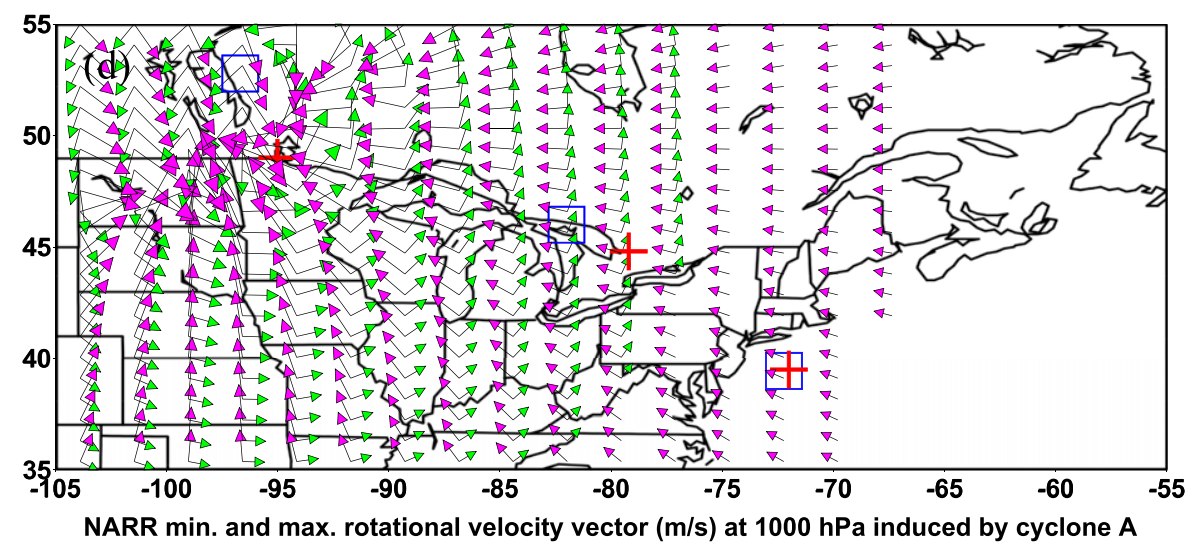

$$
\overrightarrow{1.0} 7.6
$$

NARR min. and max. divergent velocity vector $(\mathrm{m} / \mathrm{s})$ at $1000 \mathrm{hPa}$ induced by cyclone $\mathrm{A}$

$$
\overrightarrow{1.0} \underset{7.6}{\longrightarrow}
$$

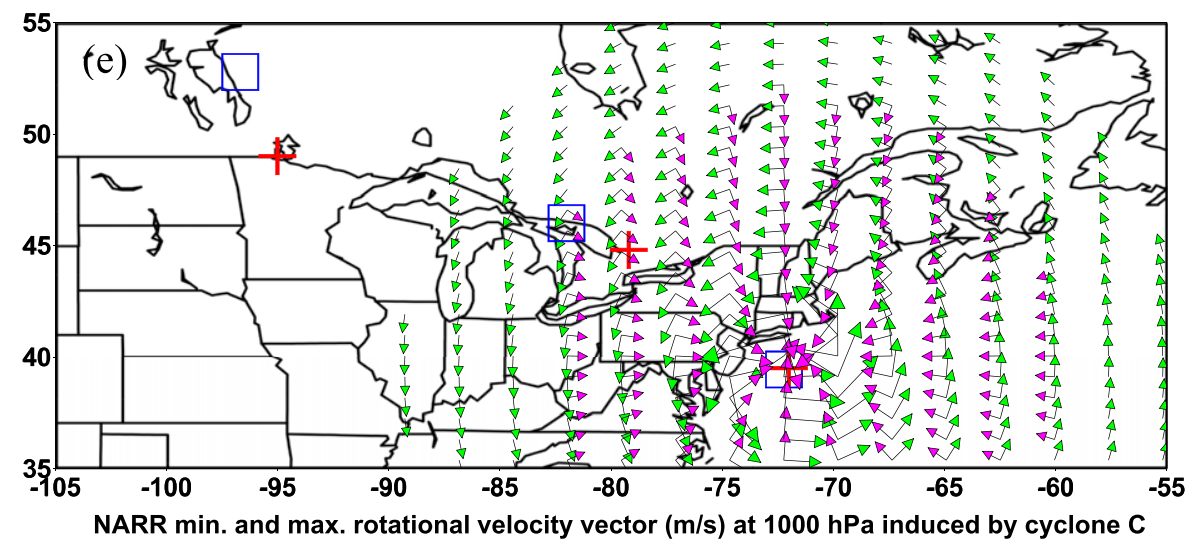

$$
\overrightarrow{1.0} \overrightarrow{12.3}
$$

NARR min. and max. divergentvelocity vector $(\mathrm{m} / \mathrm{s})$ at $1000 \mathrm{hPa}$ induced by cyclone $\mathrm{C}$

$$
\overrightarrow{1.0} \underset{12.3}{\longrightarrow}
$$

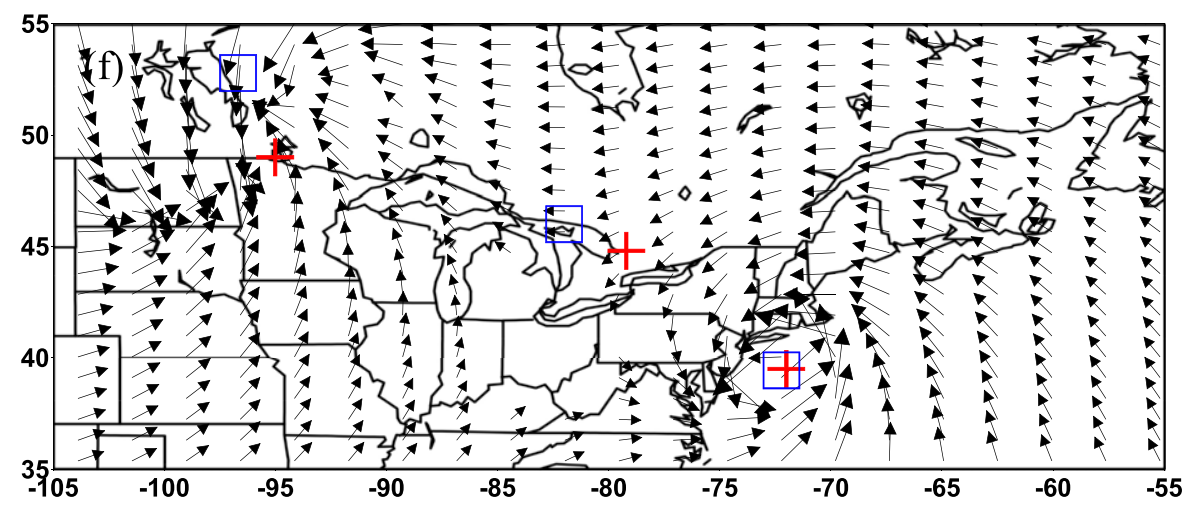

NARR min. and max. rotational and divergent velocity $(\mathrm{m} / \mathrm{s})$ at $1000 \mathrm{hPa}$ induced by cyclones A and C

$$
\overrightarrow{1.0} \underset{13.5}{\longrightarrow}
$$

FIG. 4. (Continued) 


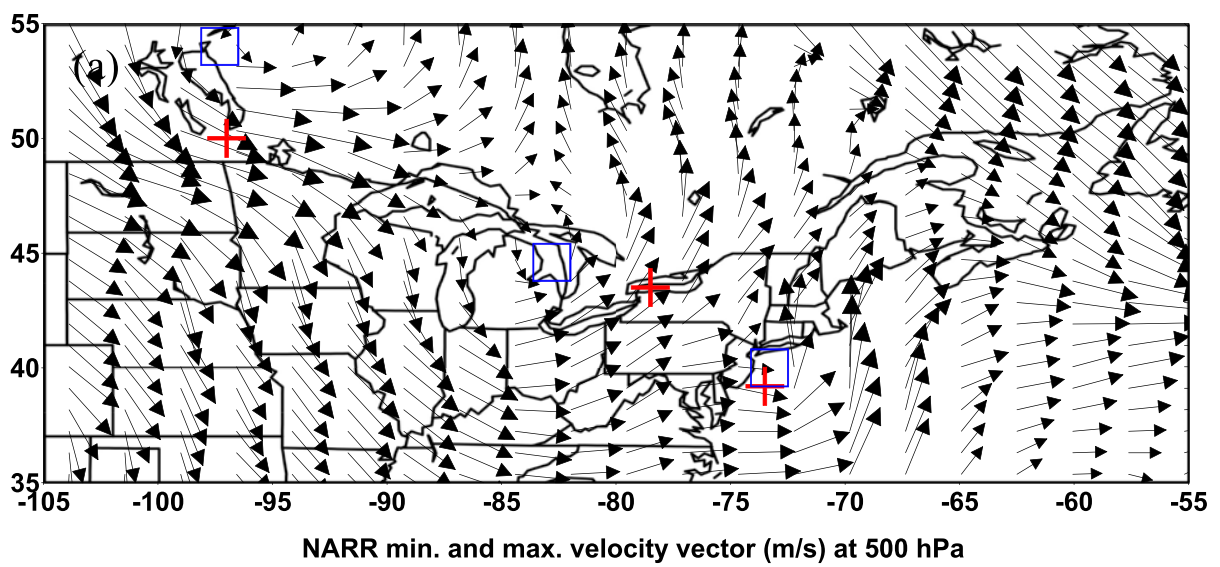
$\overrightarrow{1.0} \underset{26.0}{\longrightarrow}$

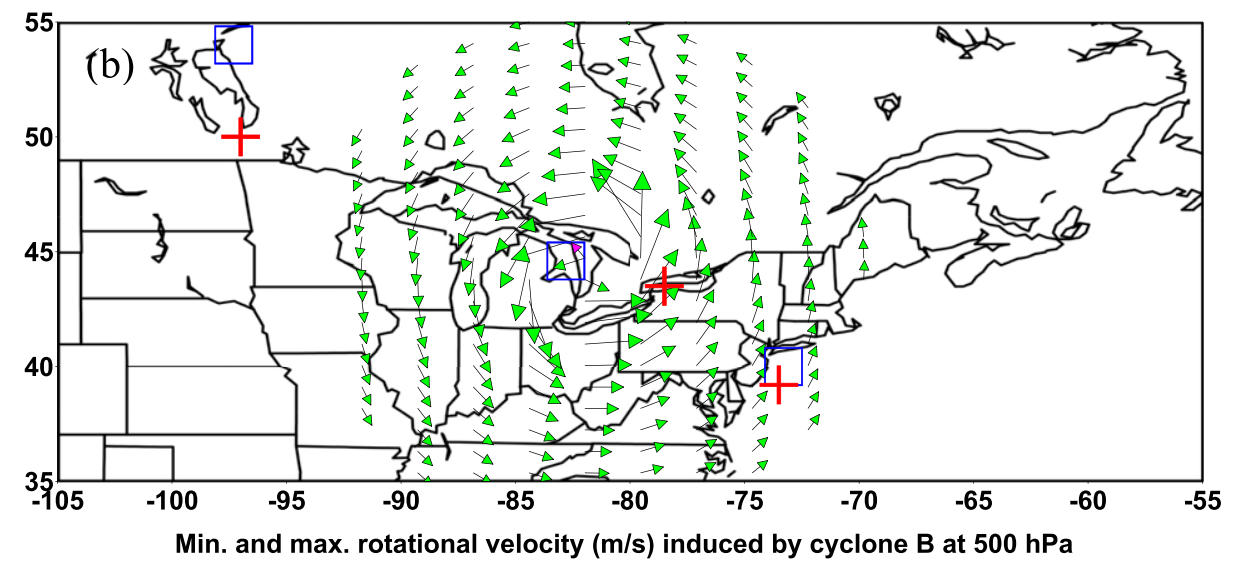

$$
\overrightarrow{1.0} 6.4
$$

Min. and max. divergent velocity $(\mathrm{m} / \mathrm{s})$ induced by cyclone $\mathrm{B}$ at $500 \mathrm{hPa}$

$$
\overrightarrow{1.0} \underset{6.4}{\longrightarrow}
$$

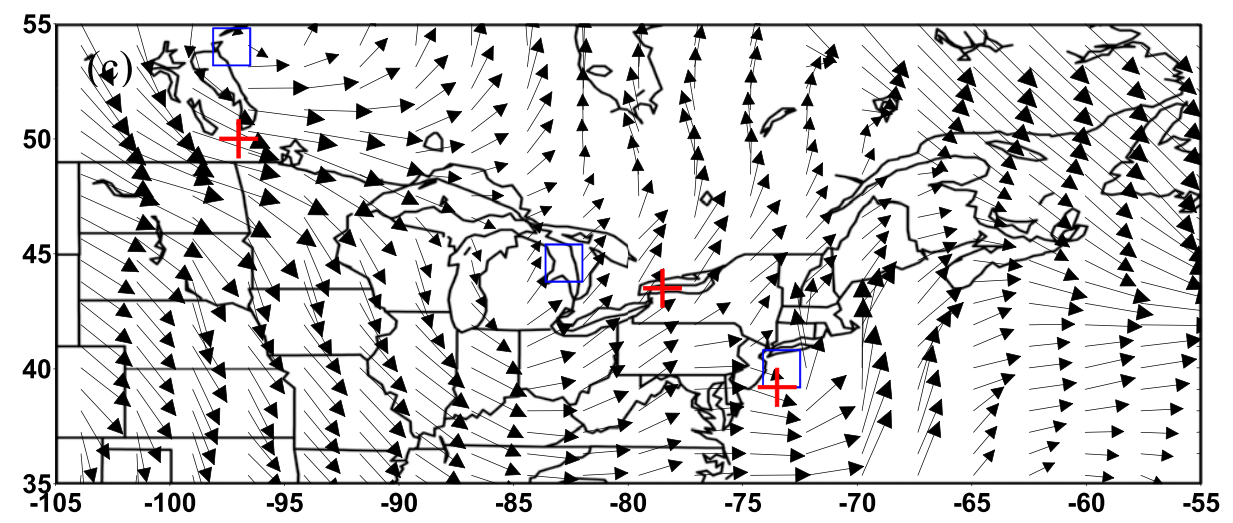

Difference between NARR total and cyclone B induced rotational and divergent velocity at $500 \mathrm{hPa}$

$$
\overrightarrow{1.0} \underset{26.0}{\longrightarrow}
$$

FIG. 5. As in Fig. 4, but at $500 \mathrm{hPa}$ at 0000 UTC 24 Jul 2009. 


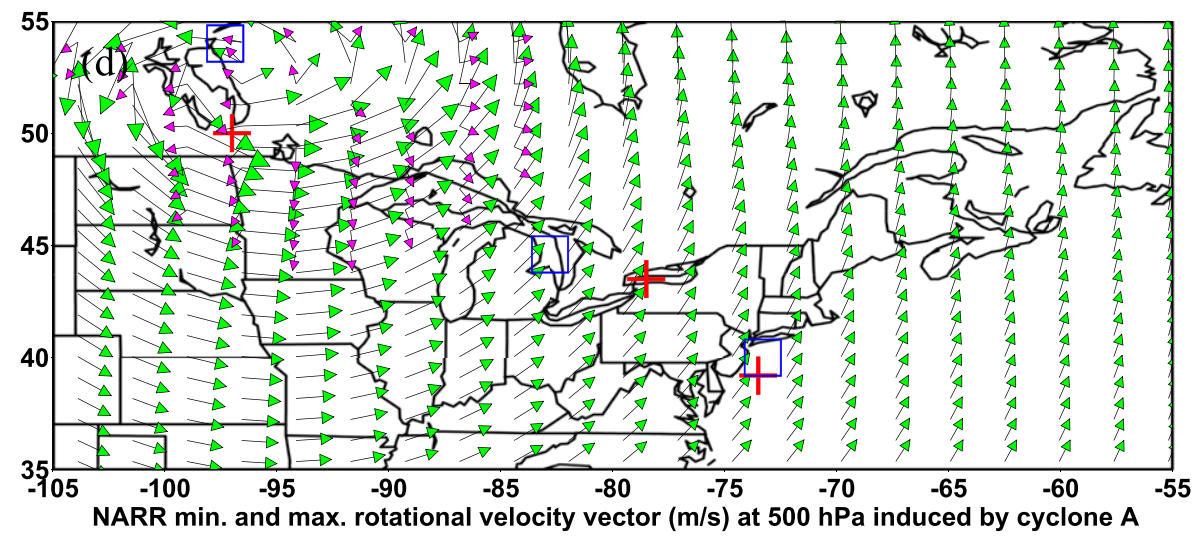

$$
\overrightarrow{1.0} \underset{14.7}{\longrightarrow}
$$

NARR min. and max. divergent velocity vector $(\mathrm{m} / \mathrm{s})$ at $500 \mathrm{hPa}$ induced by cyclone A

$$
\overrightarrow{1.0} \underset{14.7}{\longrightarrow}
$$

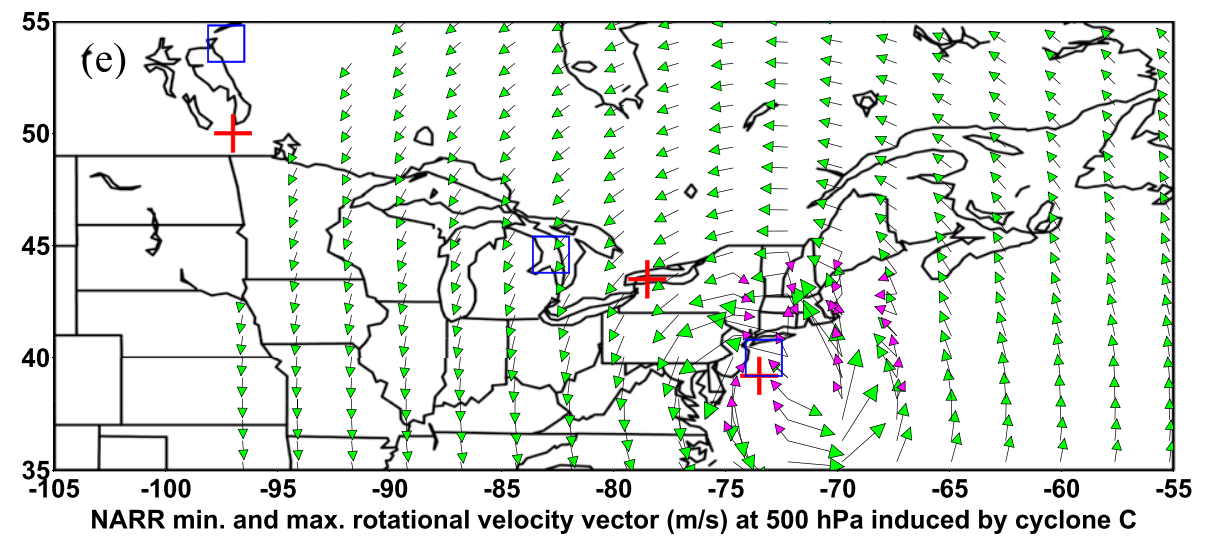

$$
\overrightarrow{1.0} \underset{14.9}{\longrightarrow}
$$

NARR min. and max. divergent velocity vector $(\mathrm{m} / \mathrm{s})$ at $500 \mathrm{hPa}$ induced by cyclone $\mathrm{C}$

$$
\overrightarrow{1.0} \underset{14.9}{\longrightarrow}
$$

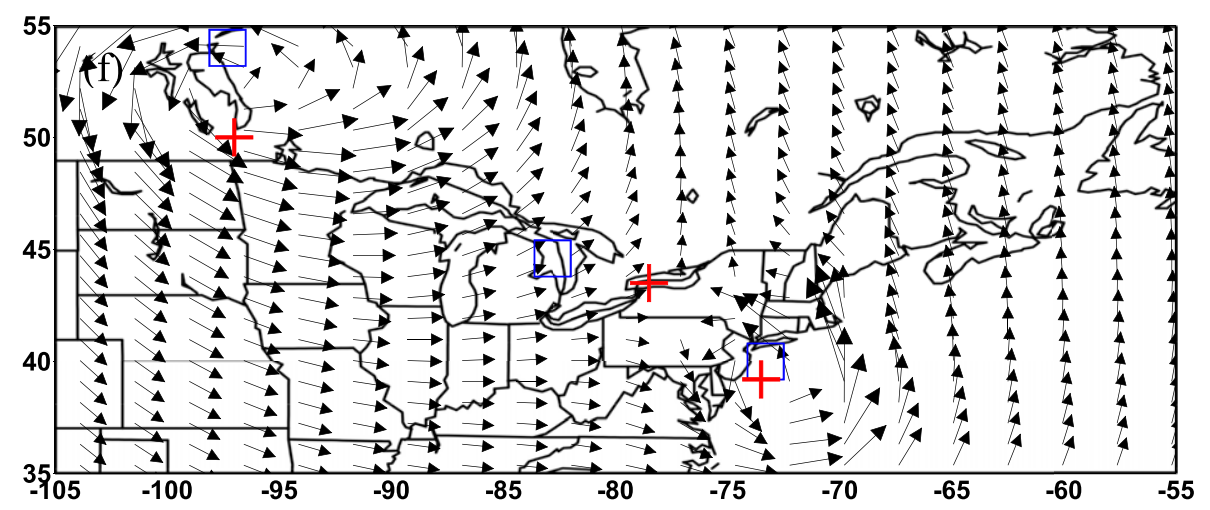

NARR min. and max. rotational and divergent velocity $(\mathrm{m} / \mathrm{s})$ at $500 \mathrm{hPa}$ induced by cyclones A and C

$$
\overrightarrow{1.0} \underset{19.1}{\longrightarrow}
$$

FIG. 5. (Continued) 


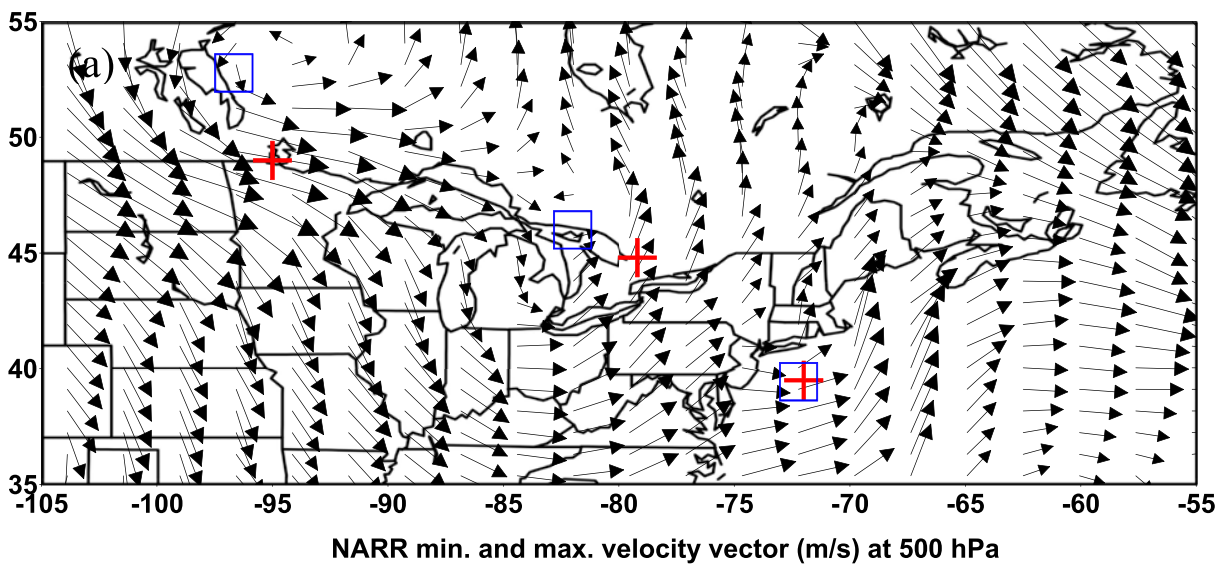

$$
\overrightarrow{1.0} \underset{30.0}{\longrightarrow}
$$

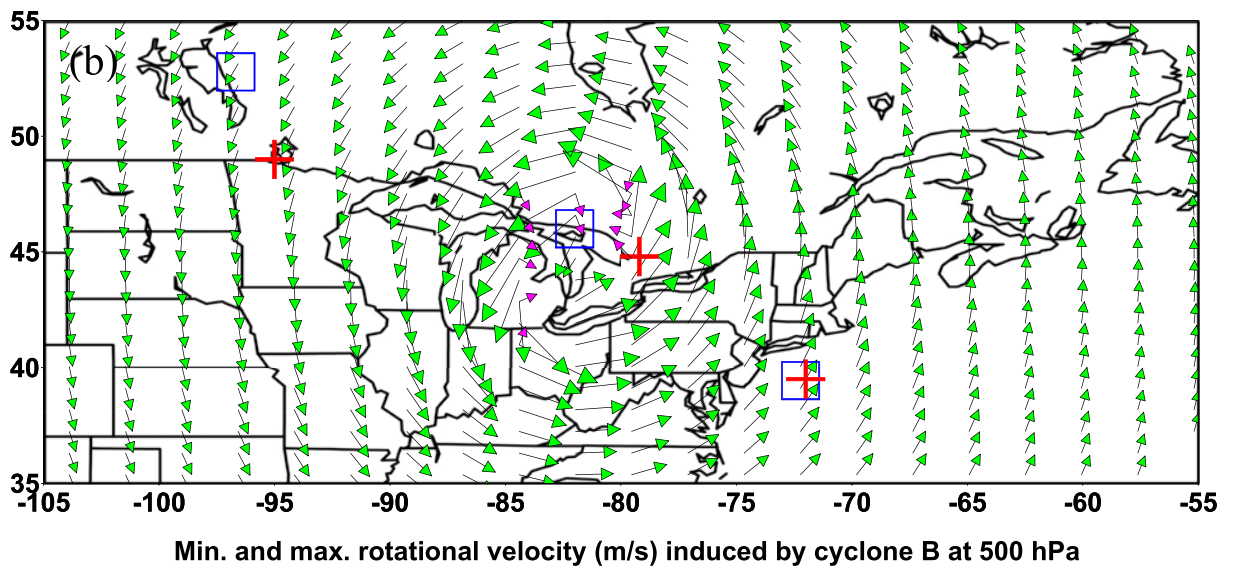

$$
\overrightarrow{1.0} \underset{9.5}{\longrightarrow}
$$

Min. and max. divergent velocity $(\mathrm{m} / \mathrm{s})$ induced by cyclone $\mathrm{B}$ at $500 \mathrm{hPa}$

$$
\overrightarrow{1.0} \underset{9.5}{\longrightarrow}
$$

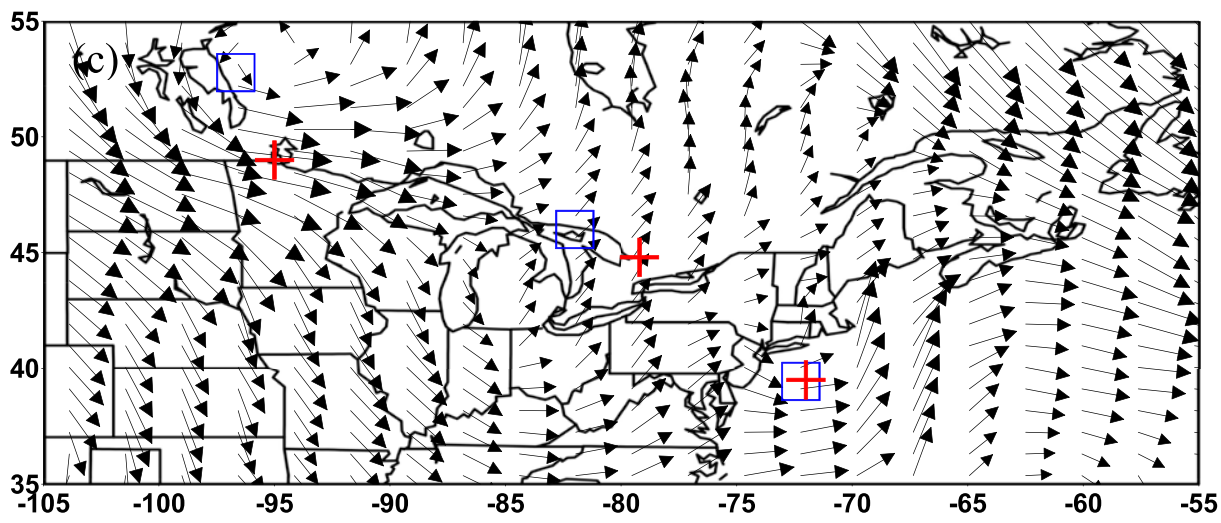

Difference between NARR total and cyclone B induced rotational and divergent velocity at $500 \mathrm{hPa}$

$$
\overrightarrow{1.0} \underset{30.0}{\longrightarrow}
$$

FIG. 6. As in Fig. 4, but at $500 \mathrm{hPa}$ at 0300 UTC 24 Jul 2009. 


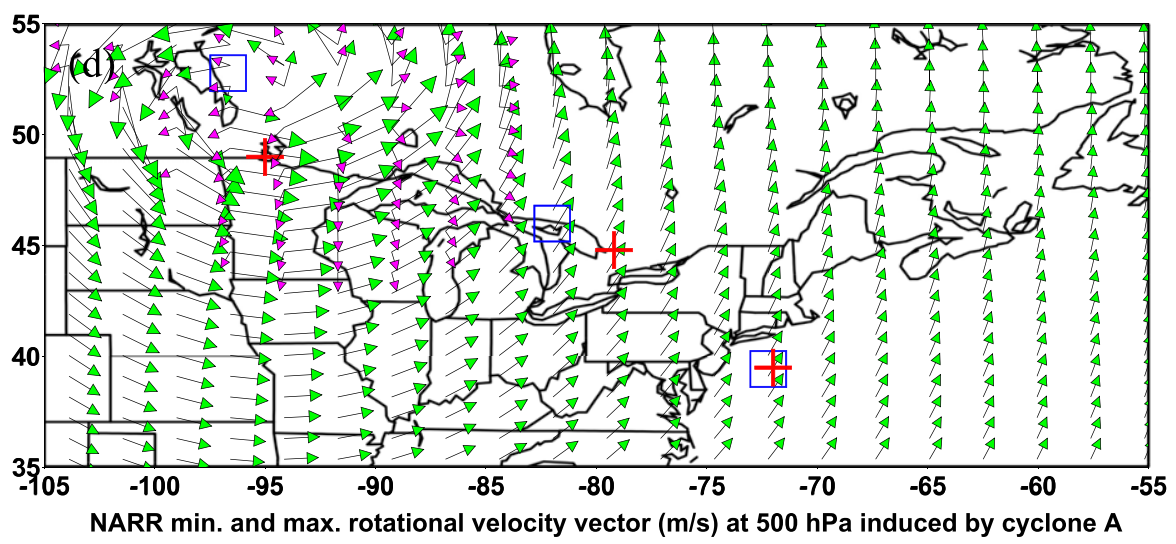

$$
\overrightarrow{1.0} \underset{17.2}{\longrightarrow}
$$

NARR min. and max. divergent velocity vector $(\mathrm{m} / \mathrm{s})$ at $500 \mathrm{hPa}$ induced by cyclone A

$$
\overrightarrow{1.0} \underset{17.2}{\longrightarrow}
$$

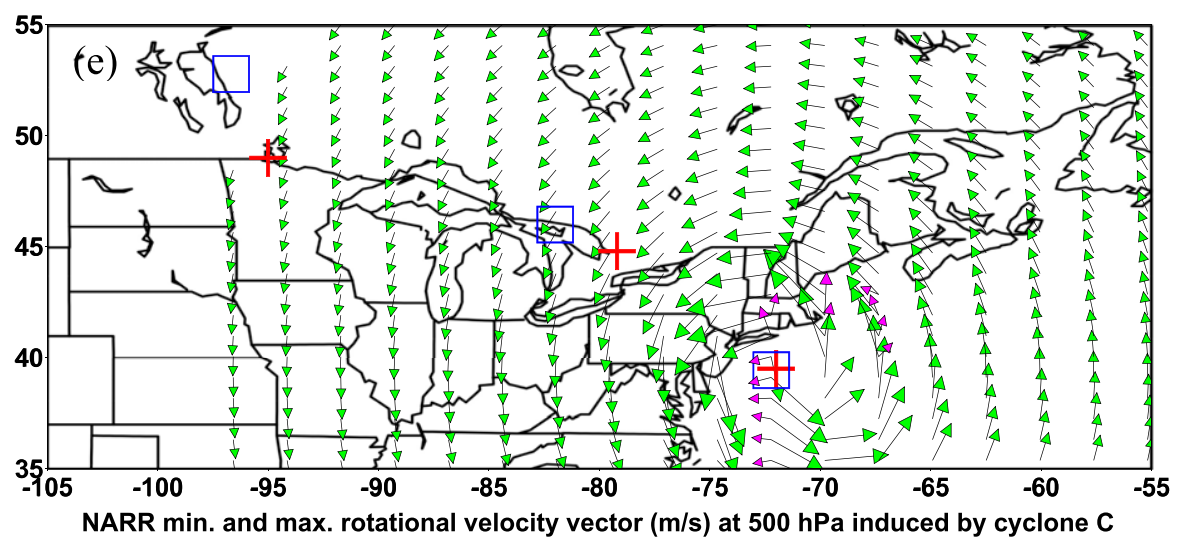

$$
\overrightarrow{1.0} \longrightarrow \mathbf{1 0 . 0}
$$

NARR min. and max. divergent velocity vector $(\mathrm{m} / \mathrm{s})$ at $500 \mathrm{hPa}$ induced by cyclone $\mathrm{C}$

$$
\overrightarrow{1.0} \underset{10.0}{\longrightarrow}
$$

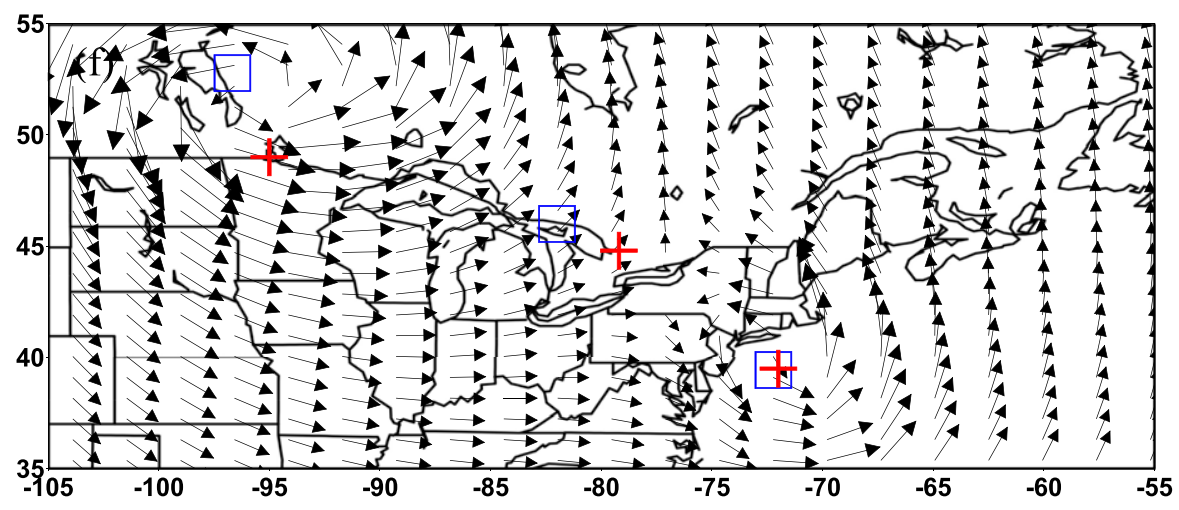

NARR min. and max. rotational and divergent velocity $(\mathrm{m} / \mathrm{s})$ at $500 \mathrm{hPa}$ induced by cyclones A and C

$$
\overrightarrow{1.0} \underset{16.6}{\longrightarrow}
$$

FIG. 6. (Continued) 


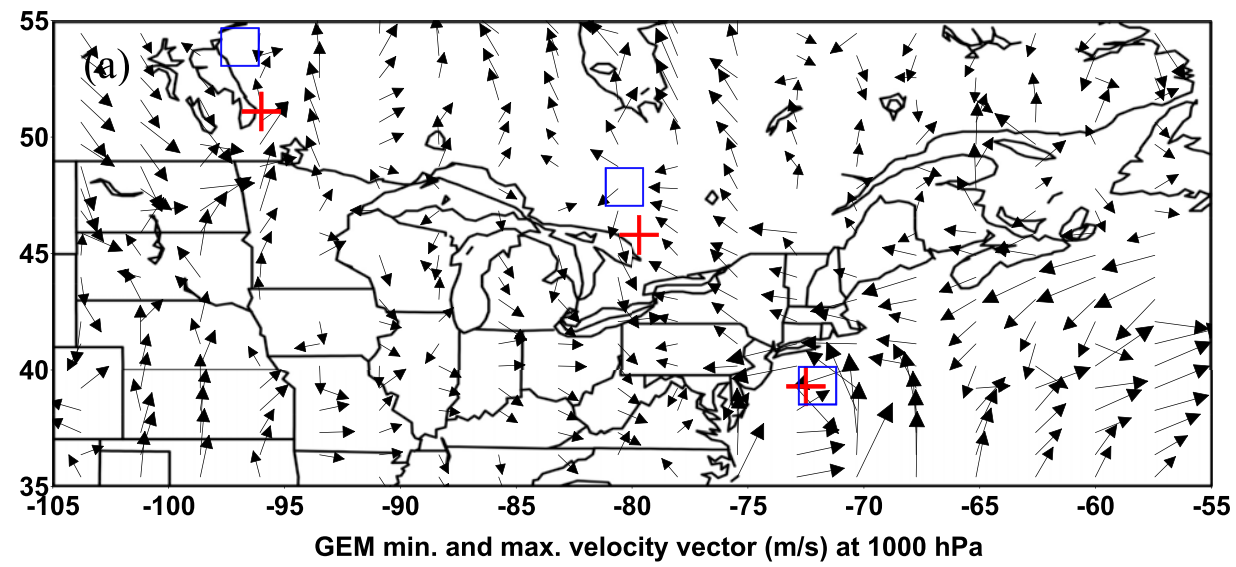

$$
\overrightarrow{1.0} \underset{17.0}{\longrightarrow}
$$

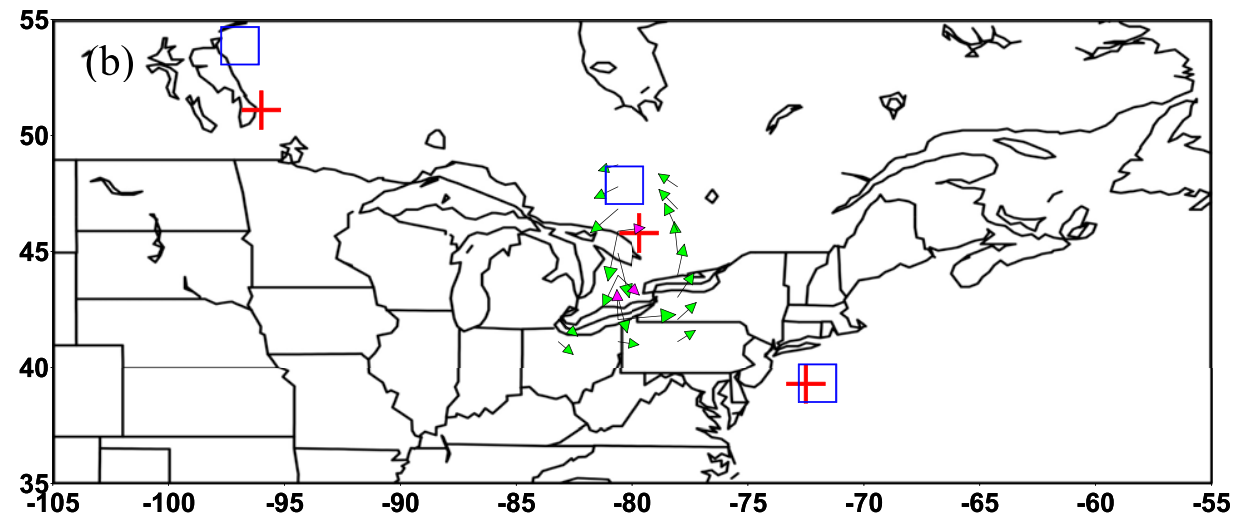

Min. and max. rotational velocity vector $(\mathrm{m} / \mathrm{s})$ induced by cyclone $\mathrm{B}$ at $1000 \mathrm{hPa}$

$$
\overrightarrow{1.0} \underset{6.0}{\longrightarrow}
$$

Min. and max. divergent velocity vector $(\mathrm{m} / \mathrm{s})$ induced by cyclone $\mathrm{B}$ at $1000 \mathrm{hPa}$

$$
\overrightarrow{1.0} \underset{6.0}{\longrightarrow}
$$

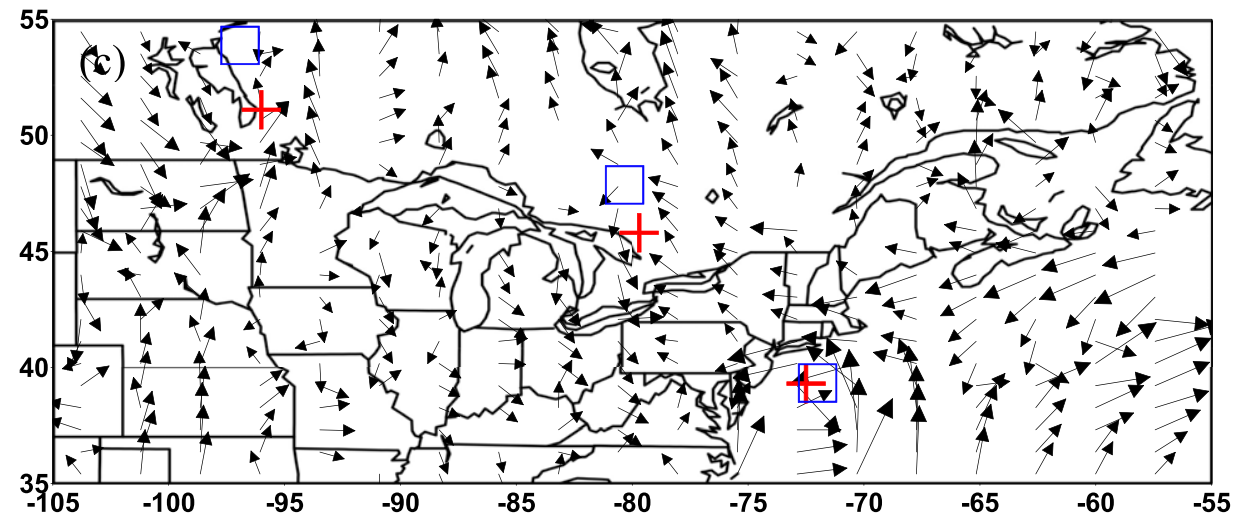

Difference between GEM total and cyclone B induced rotational and divergent velocity $(\mathrm{m} / \mathrm{s})$ at $1000 \mathrm{hPa}$

$$
\overrightarrow{1.0} \underset{17.0}{\longrightarrow}
$$

FIG. 7. (a) GEM model horizontal velocity vectors $\left(\mathrm{m} \mathrm{s}^{-1}\right)$, (b) cyclone B-induced rotational flow ( $\mathrm{m} \mathrm{s}^{-1}$; green) and divergent flow ( $\mathrm{m} \mathrm{s}^{-1}$; purple), (c) environmental flow [ $\mathrm{m} \mathrm{s}^{-1}$; (a) minus (b)], (d) cyclone A-induced rotational flow $\left(\mathrm{m} \mathrm{s}^{-1}\right.$; green) and divergent flow $\left(\mathrm{m} \mathrm{s}^{-1}\right.$; purple), (e) cyclone C-induced rotational flow $\left(\mathrm{m} \mathrm{s}^{-1}\right.$; green) and divergent flow ( $\mathrm{m} \mathrm{s}^{-1}$; purple), and (f) both cyclones A and C-induced flow [m s${ }^{-1}$; (d) plus (e)] at $1000 \mathrm{hPa}$ at 0000 UTC $24 \mathrm{Jul} 2009$. Plus signs and squares respectively denote the geographic locations for centers of 1000- and 500-hPa cyclones $\mathrm{A}, \mathrm{B}$, and $\mathrm{C}$, from left to right. 


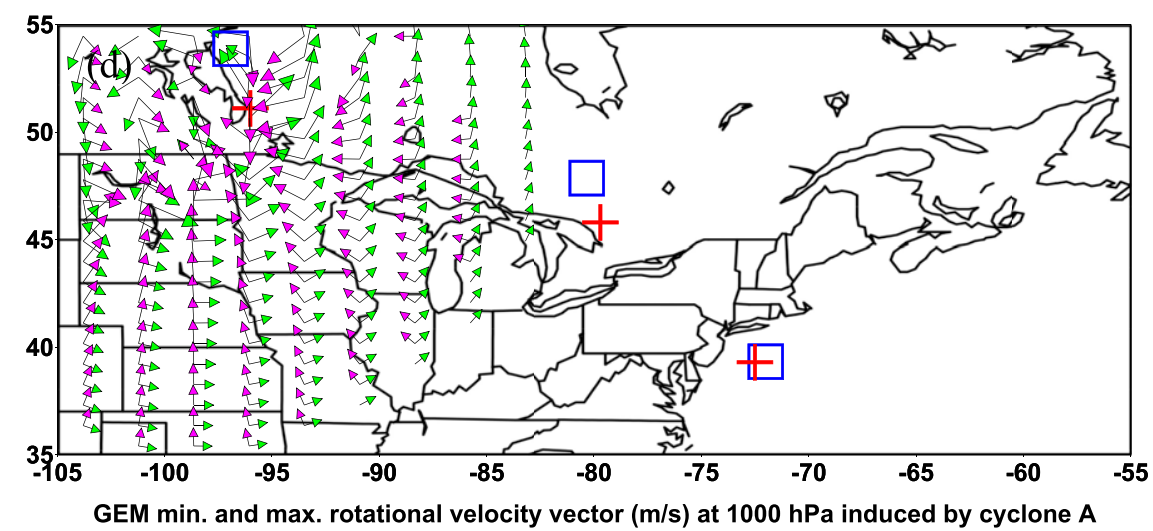

$$
\overrightarrow{1.0} \underset{7.9}{\longrightarrow}
$$

GEM min. and max. divergent velocity vector $(\mathrm{m} / \mathrm{s})$ at $1000 \mathrm{hPa}$ induced by cyclone $A$

$$
\overrightarrow{1.0} \underset{7.9}{\longrightarrow}
$$

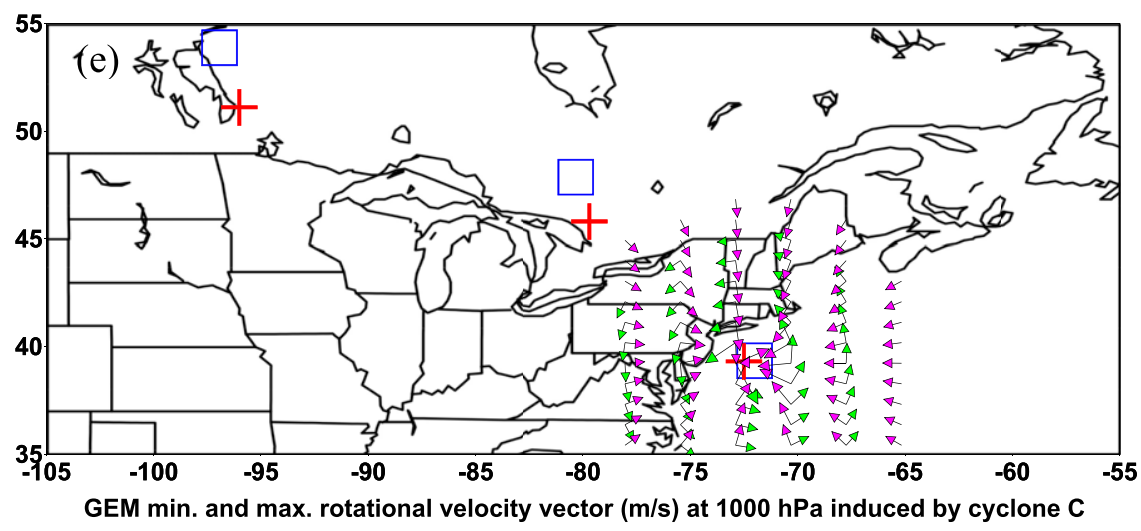

$$
\overrightarrow{1.0} \underset{17.0}{\longrightarrow}
$$

GEM min. and max. divergent velocity vector $(\mathrm{m} / \mathrm{s})$ at $1000 \mathrm{hPa}$ induced by cyclone $\mathrm{C}$

$$
\overrightarrow{1.0} \underset{17.0}{\longrightarrow}
$$

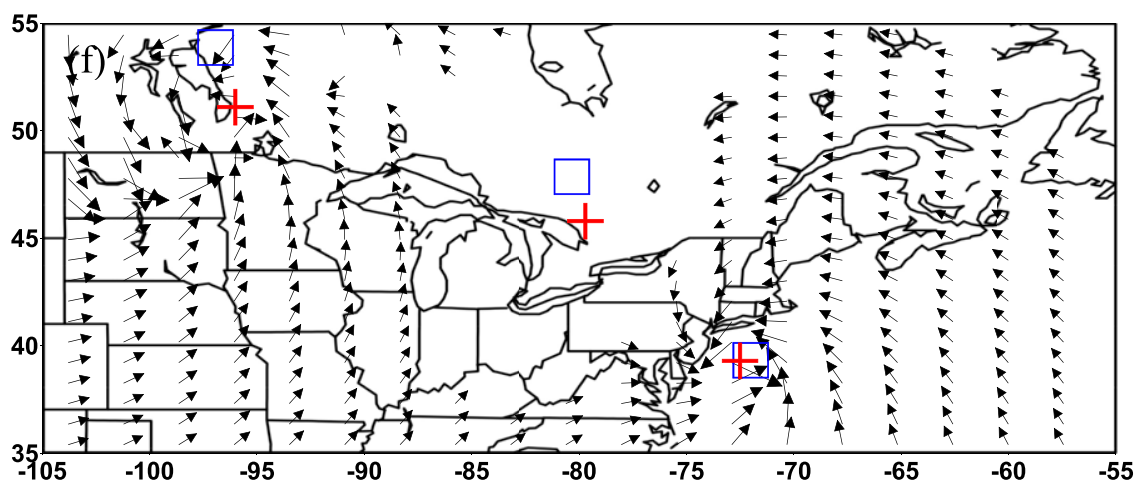

GEM min. and max. rotational and divergent velocity $(\mathrm{m} / \mathrm{s})$ at $1000 \mathrm{hPa}$ induced by cyclones $\mathrm{A}$ and $\mathrm{C}$

$$
\overrightarrow{1.0} \underset{16.0}{\longrightarrow}
$$

FIG. 7. (Continued) 


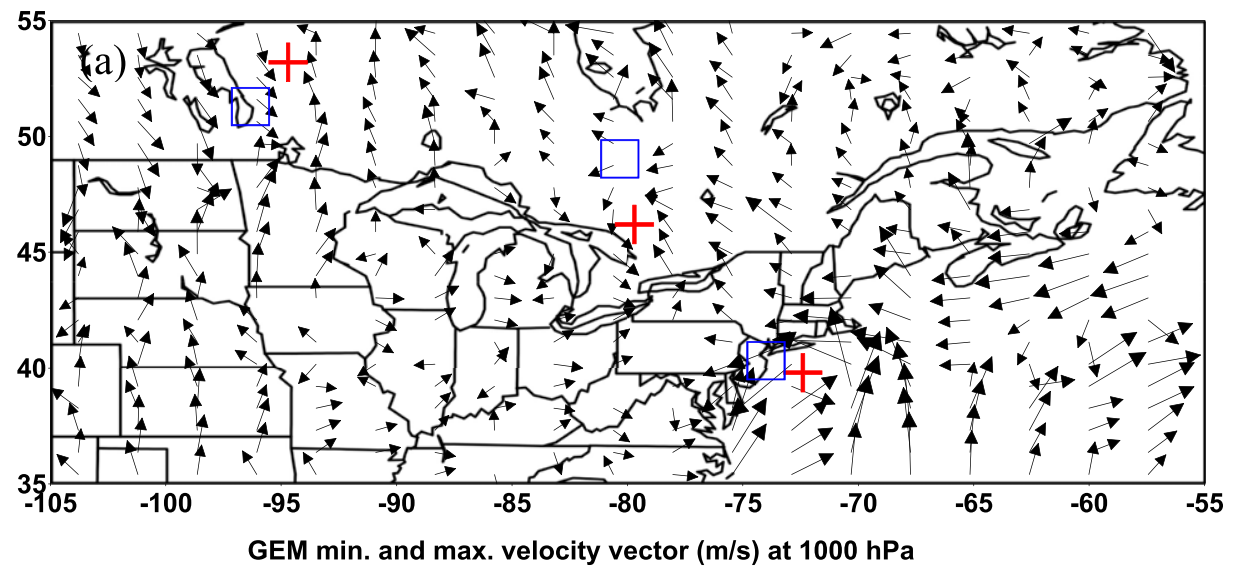

$$
\overrightarrow{1.0} \underset{19.0}{\longrightarrow}
$$

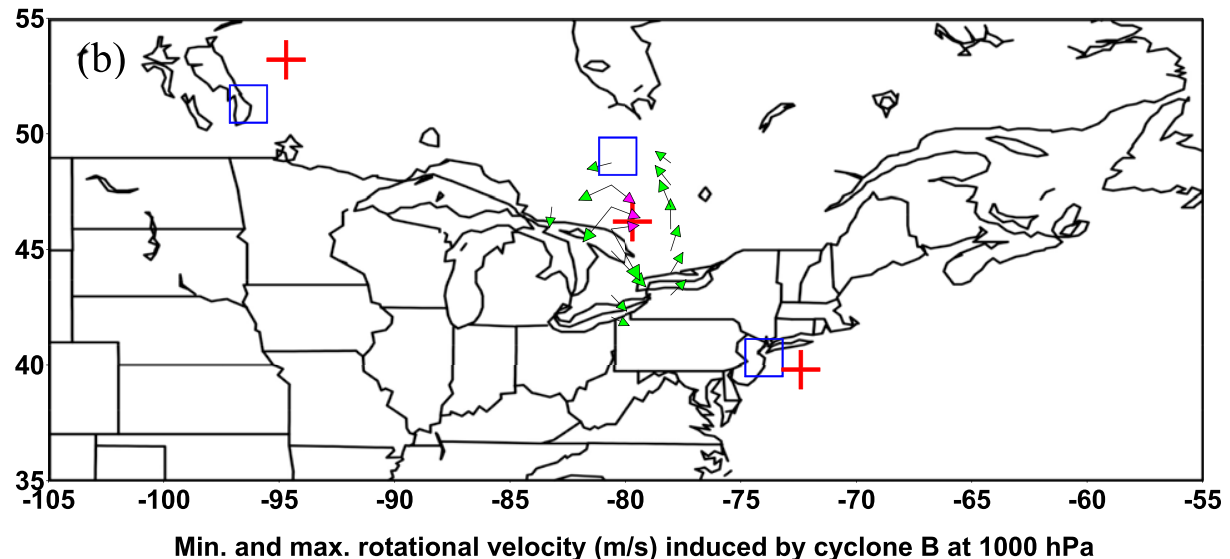

$$
\overrightarrow{1.0} \longrightarrow
$$

Min. and max. divergent velocity $(\mathrm{m} / \mathrm{s})$ induced by cyclone $\mathrm{B}$ at $1000 \mathrm{hPa}$

$$
\overrightarrow{1.0}
$$

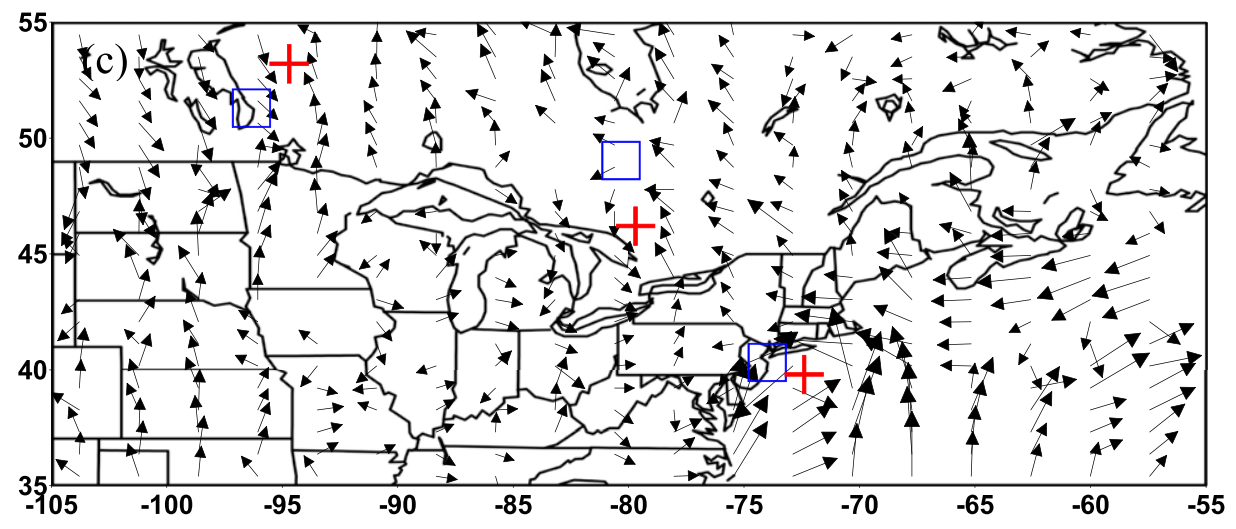

Difference between GEM total and cyclone B induced rotational and divergent velocity $(\mathrm{m} / \mathrm{s})$ at $1000 \mathrm{hPa}$

$$
\overrightarrow{1.0} \underset{19.0}{\longrightarrow}
$$

FIG. 8. As in Fig. 7, but at $1000 \mathrm{hPa}$ at 0300 UTC 24 Jul 2009. 


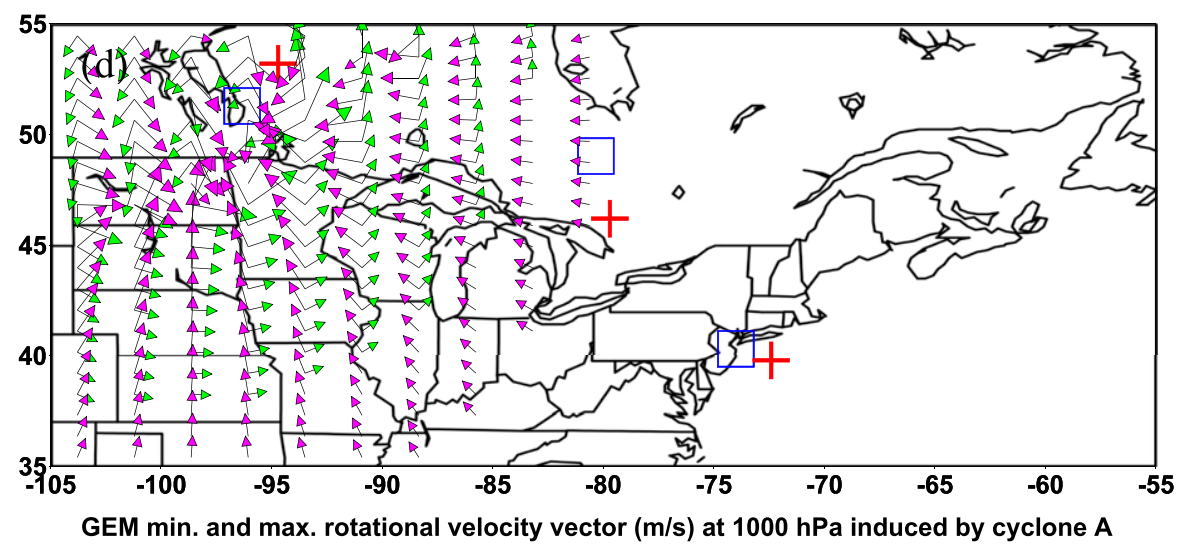

$$
\overrightarrow{1.0} \underset{5.7}{\longrightarrow}
$$

GEM min. and max. divergent velocity vector $(\mathrm{m} / \mathrm{s})$ at $1000 \mathrm{hPa}$ induced by cyclone $A$

$$
\overrightarrow{1.0} \underset{5.7}{\longrightarrow}
$$

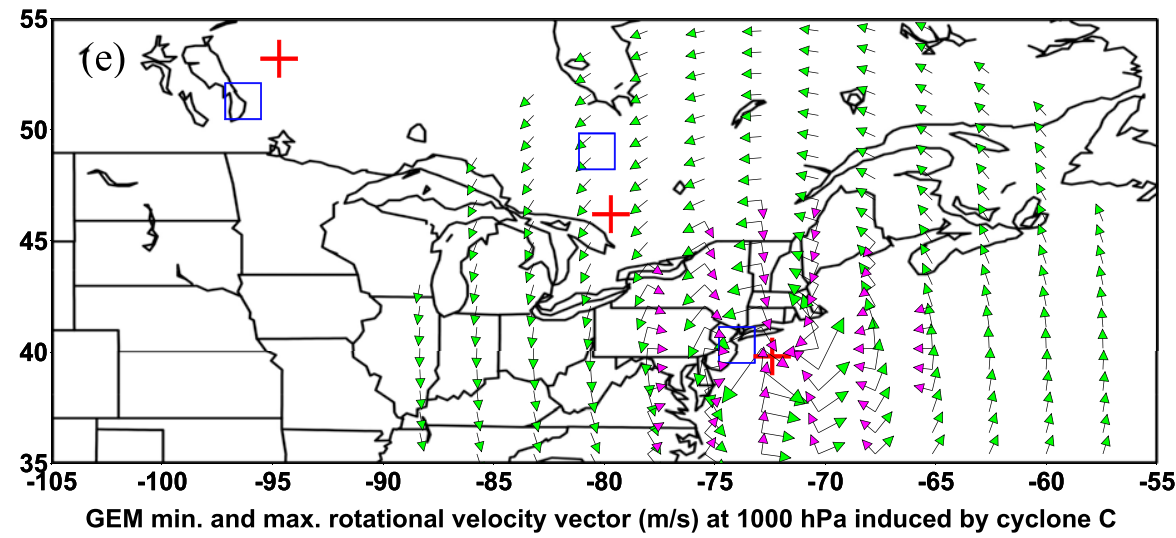

$$
\overrightarrow{1.0} \underset{17.9}{\longrightarrow}
$$

GEM min. and max. divergent velocity vector $(\mathrm{m} / \mathrm{s})$ at $1000 \mathrm{hPa}$ induced by cyclone $\mathrm{C}$

$$
\overrightarrow{1.0} \underset{17.9}{\longrightarrow}
$$

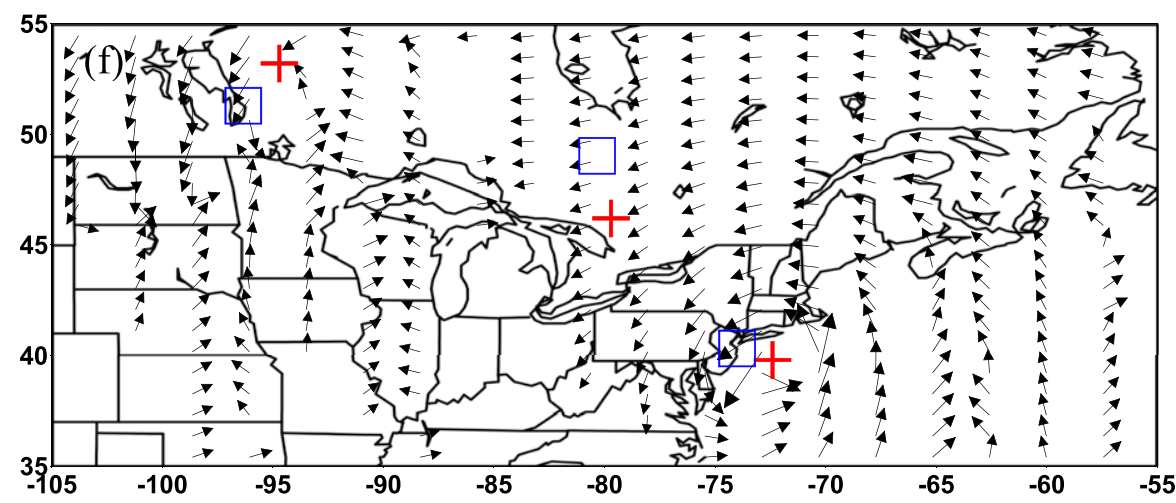

GEM min. and max. rotational and divergent velocity $(\mathrm{m} / \mathrm{s})$ at $1000 \mathrm{hPa}$ induced by cyclones $\mathrm{A}$ and $\mathrm{C}$

$$
\overrightarrow{1.0} \underset{20.7}{\longrightarrow}
$$

FIG. 8. (Continued) 


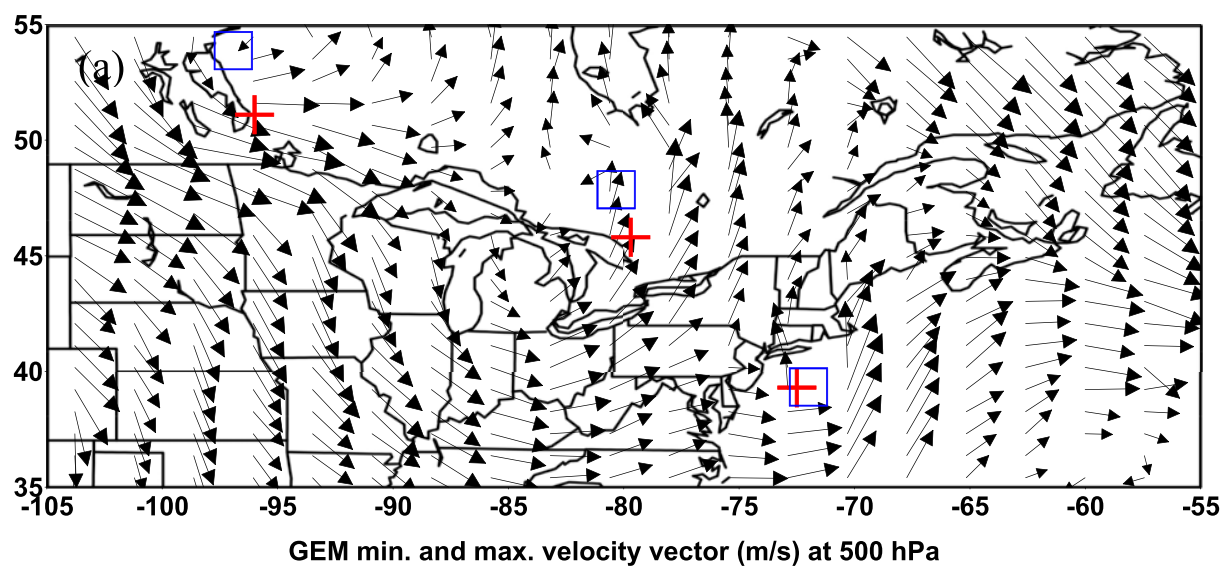

$\overrightarrow{1.0} \underset{30.0}{\longrightarrow}$

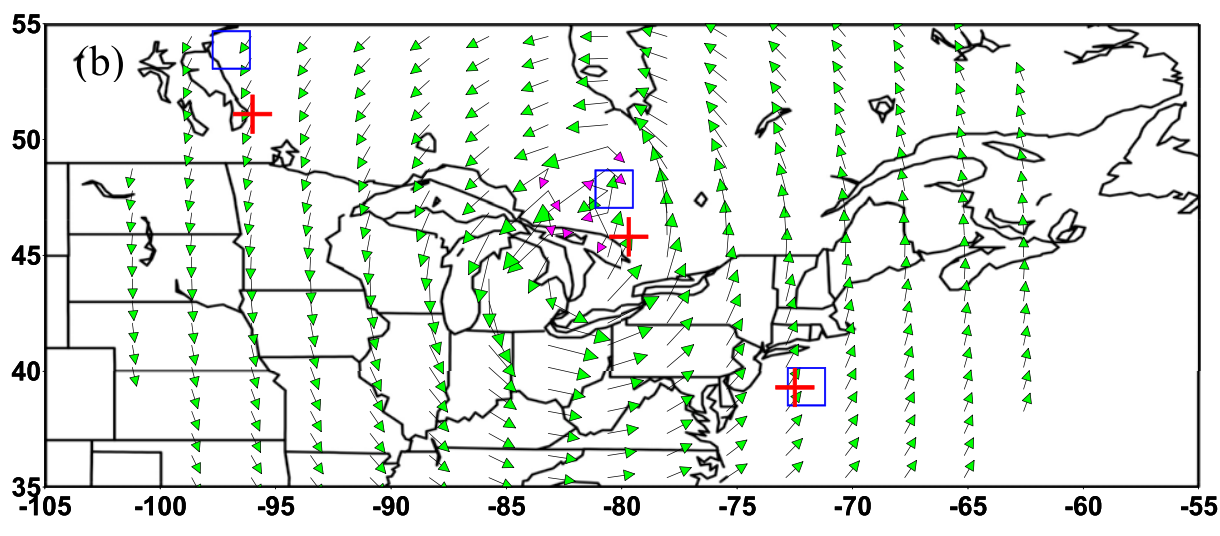

Min. and max. rotational velocity vector $(\mathrm{m} / \mathrm{s})$ induced by cyclone B at $500 \mathrm{hPa}$

$$
\overrightarrow{1.0} \underset{12.0}{\longrightarrow}
$$

Min. and max. divergent velocity vector $(\mathrm{m} / \mathrm{s})$ induced by cyclone $\mathrm{B}$ at $500 \mathrm{hPa}$

$\overrightarrow{1.0} \underset{12.0}{\longrightarrow}$

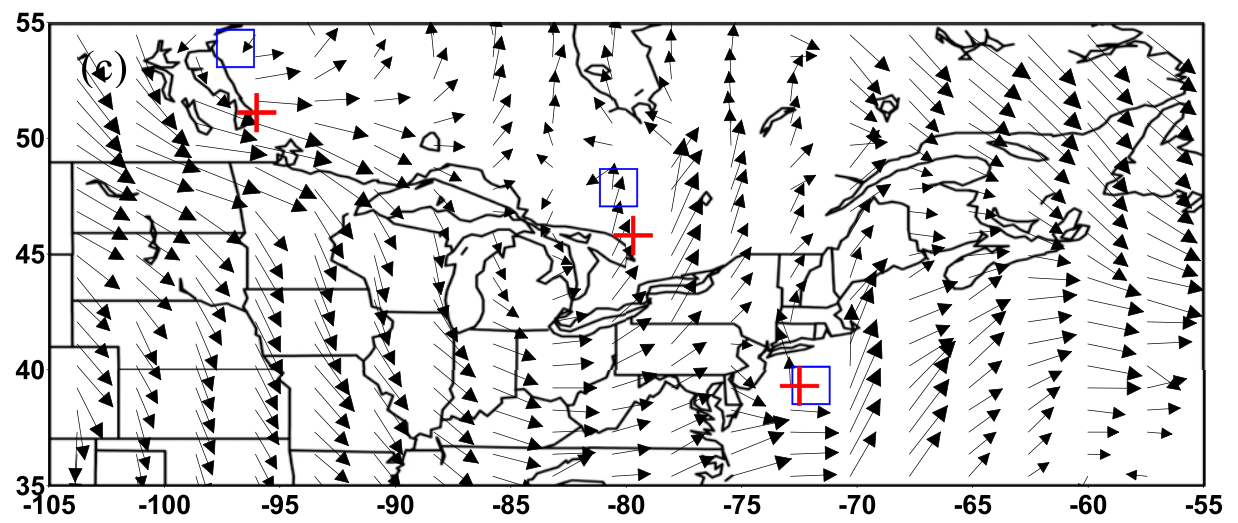

Difference between GEM total and cyclone B induced rotational and divergent velocity $(\mathrm{m} / \mathrm{s})$ at $500 \mathrm{hPa}$

$$
\overrightarrow{\mathbf{1 . 0}} \overrightarrow{\mathbf{3 7 . 0}}
$$

FIG. 9. As in Fig. 7, but at $500 \mathrm{hPa}$ at 0000 UTC 24 Jul 2009. 


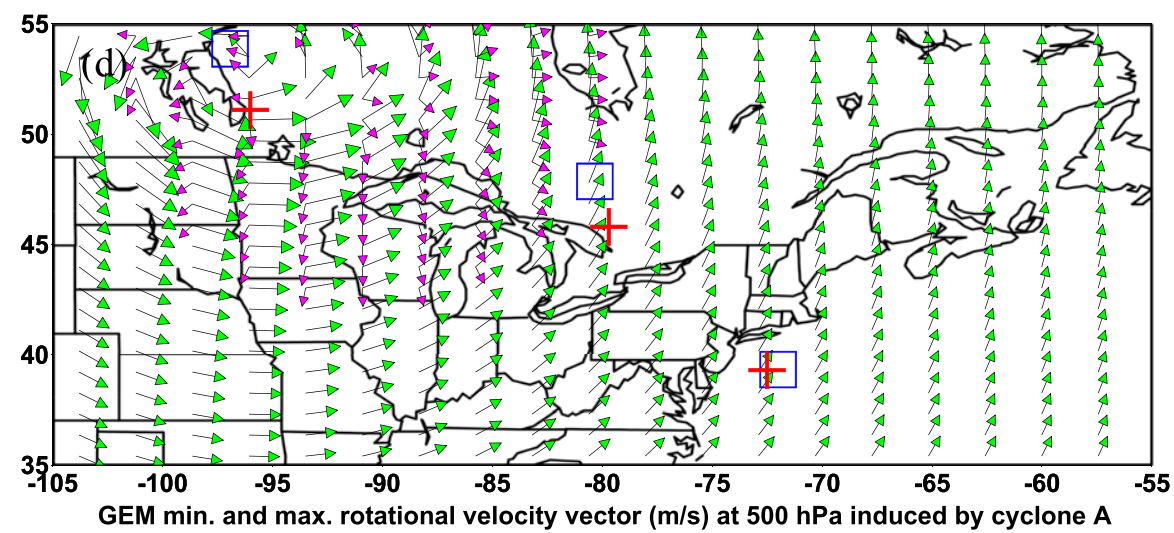

$$
\rightarrow \longrightarrow 20
$$

GEM min. and max. divergent velocity vector $(\mathrm{m} / \mathrm{s})$ at $500 \mathrm{hPa}$ induced by cyclone $\mathrm{A}$

$$
\rightarrow \longrightarrow 20.0
$$

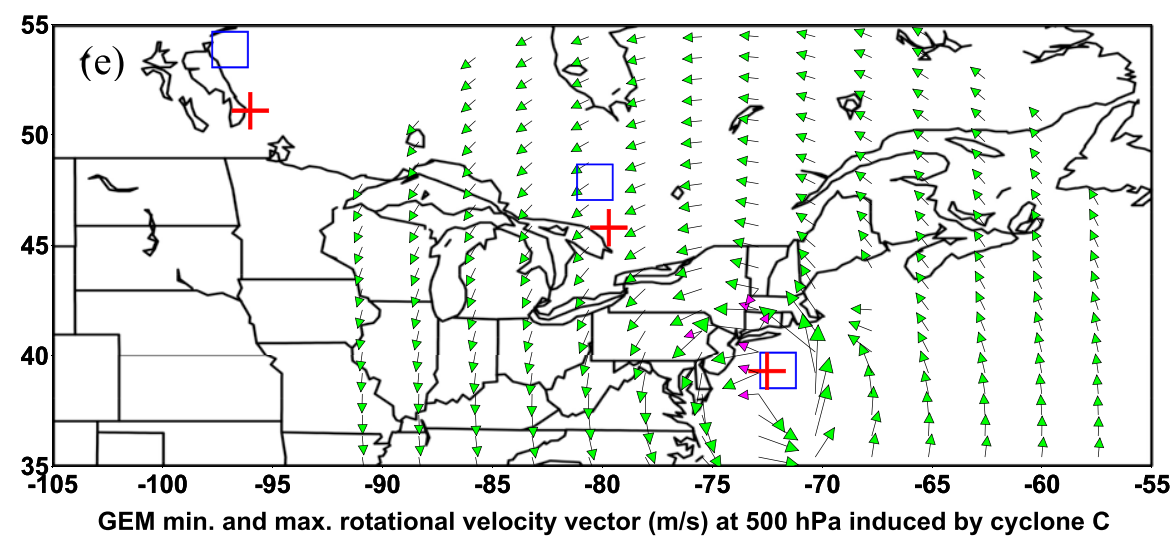

$$
\overrightarrow{1.0} \underset{21.0}{\longrightarrow}
$$

GEM min. and max. divergent velocity vector $(\mathrm{m} / \mathrm{s})$ at $500 \mathrm{hPa}$ induced by cyclone $\mathrm{C}$

$$
\overrightarrow{1.0} \underset{21.0}{\longrightarrow}
$$

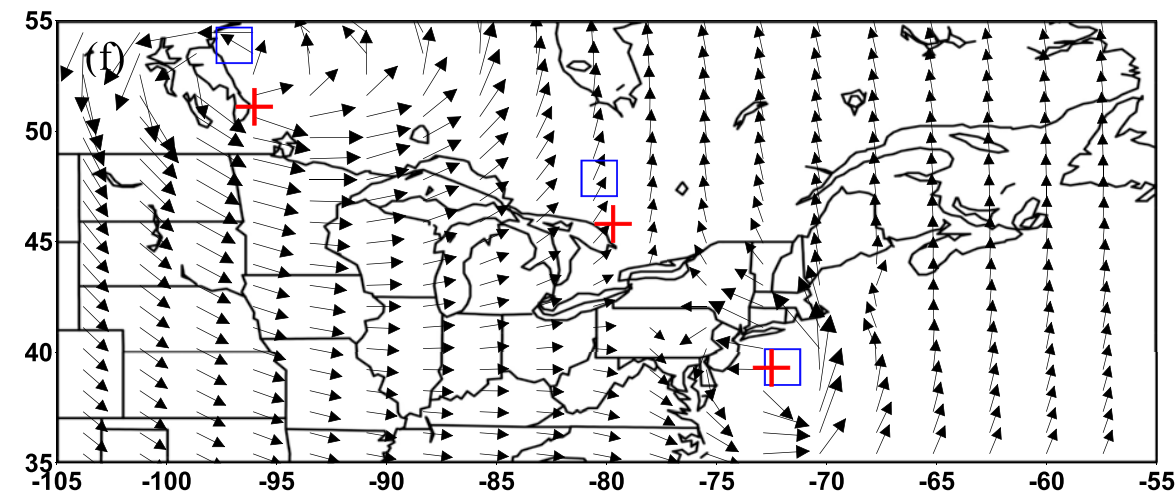

GEM min. and max. rotational and divergent velocity $(\mathrm{m} / \mathrm{s})$ at $500 \mathrm{hPa}$ induced by cyclones $\mathrm{A}$ and $\mathrm{C}$

$$
\overrightarrow{1.0} \underset{21.4}{\longrightarrow}
$$

FIG. 9. (Continued) 


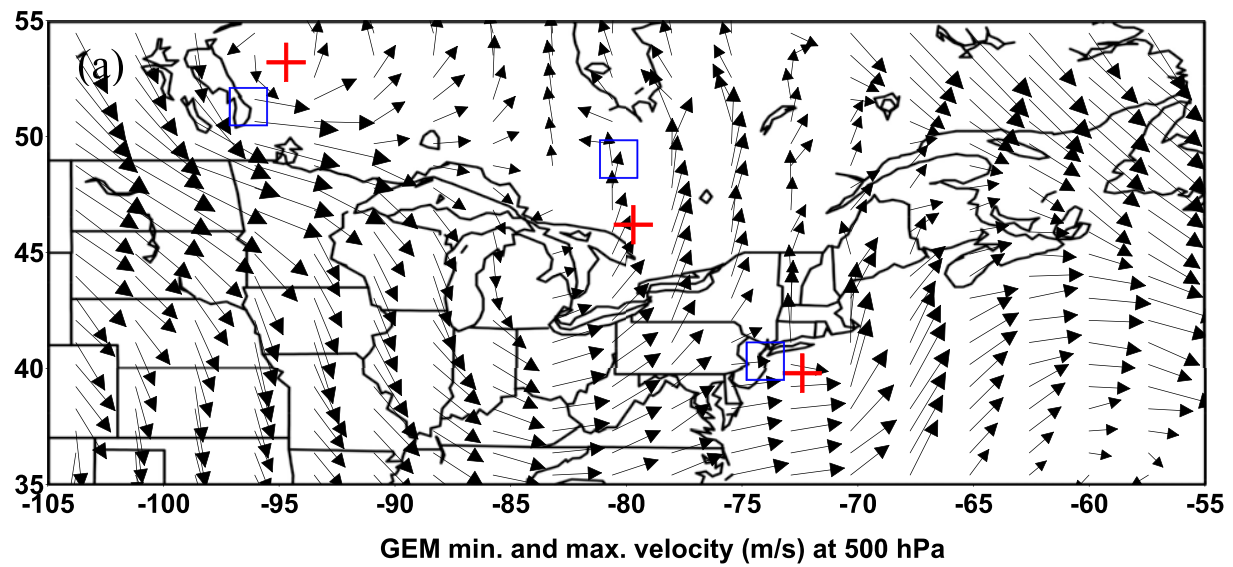

$$
\overrightarrow{1.0} \underset{29.0}{\longrightarrow}
$$

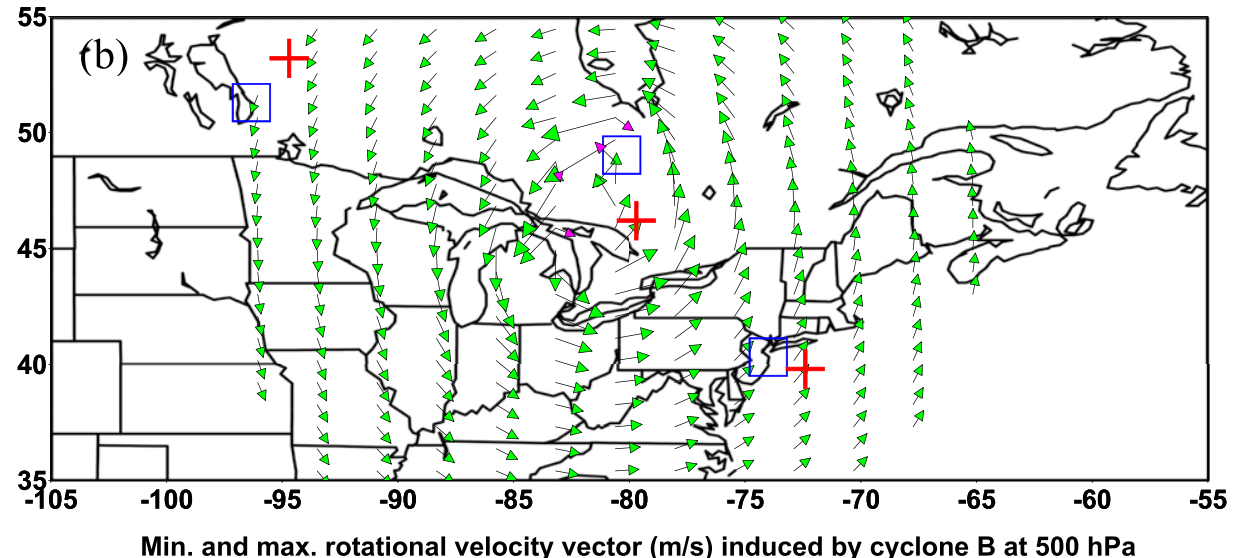

$$
\overrightarrow{1.0} \underset{10.6}{\longrightarrow}
$$

Min. and max. divergent velocity vector $(\mathrm{m} / \mathrm{s})$ induced by cyclone $\mathrm{B}$ at $500 \mathrm{hPa}$

$$
\overrightarrow{1.0} \underset{10.6}{\longrightarrow}
$$

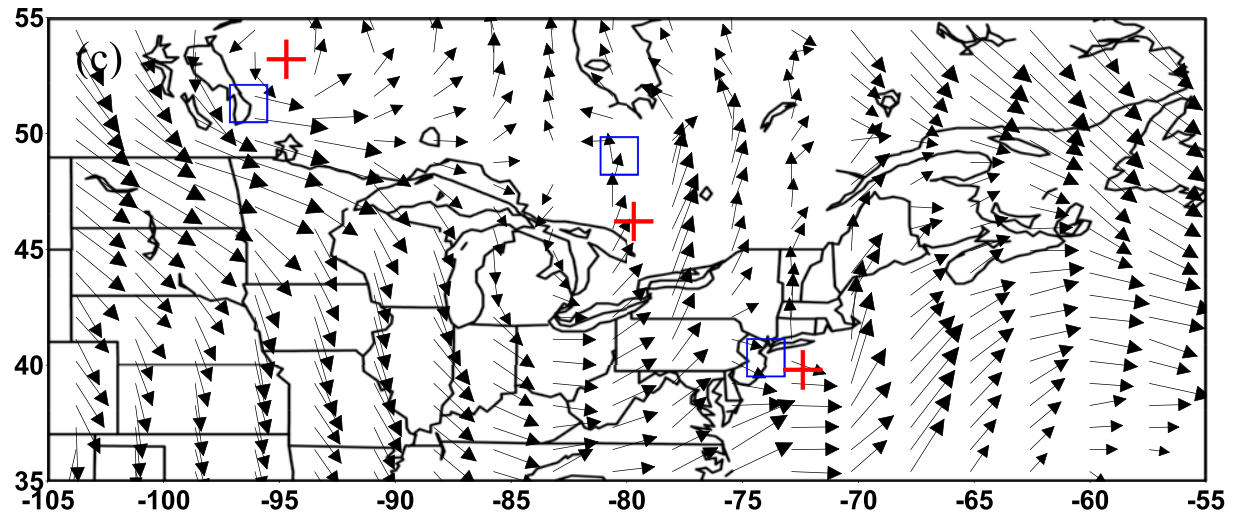

Difference between GEM total and cyclone B induced rotational and divergent velocity $(\mathrm{m} / \mathrm{s})$ at $500 \mathrm{hPa}$

$$
\overrightarrow{1.0} \underset{34.0}{\longrightarrow}
$$

FIG. 10. As in Fig. 7, but at $500 \mathrm{hPa}$ at 0300 UTC 24 Jul 2009. 


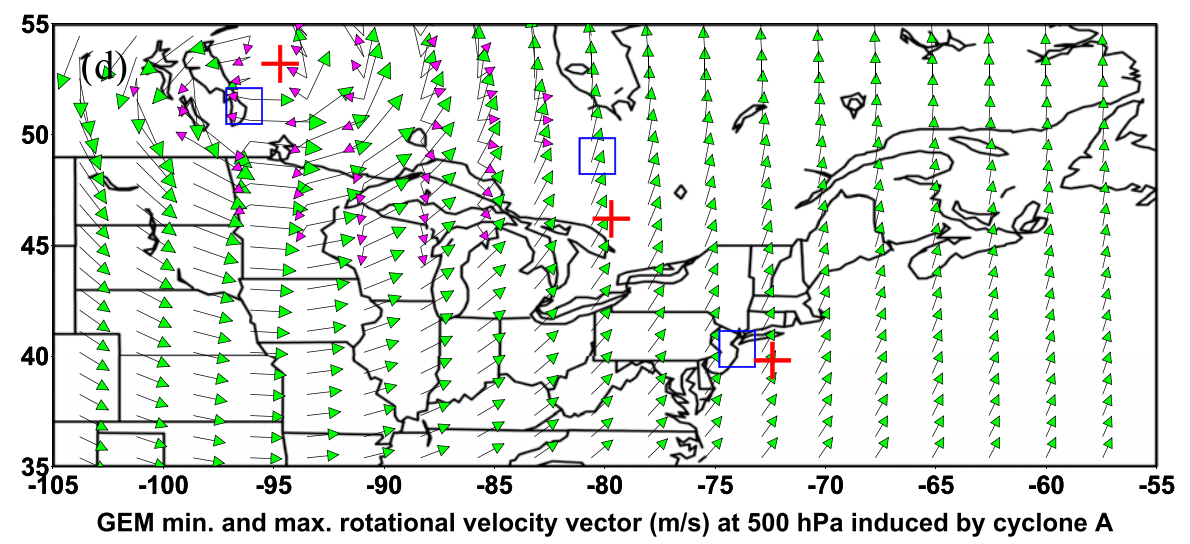

$$
\overrightarrow{1.0} \underset{20.0}{\longrightarrow}
$$

GEM min. and max. divergent velocity vector $(\mathrm{m} / \mathrm{s})$ at $500 \mathrm{hPa}$ induced by cyclone $A$

$$
\rightarrow \overrightarrow{20.0}
$$

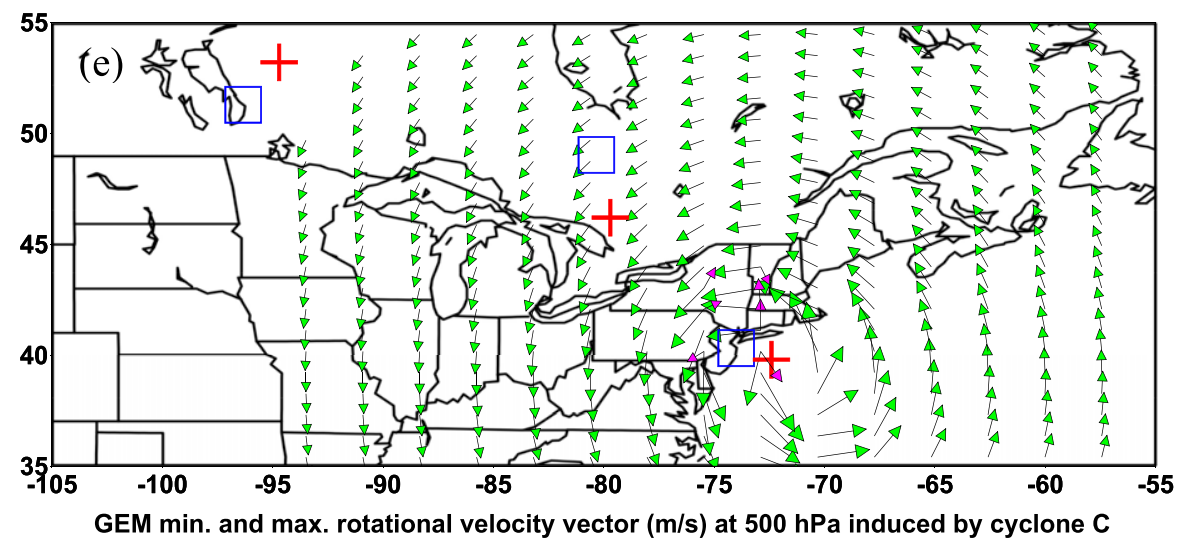

$$
\overrightarrow{1.0} \underset{13.9}{\longrightarrow}
$$

GEM min. and max. divergent velocity vector $(\mathrm{m} / \mathrm{s})$ at $500 \mathrm{hPa}$ induced by cyclone $\mathrm{C}$

$$
\overrightarrow{1.0} \underset{13.9}{\longrightarrow}
$$

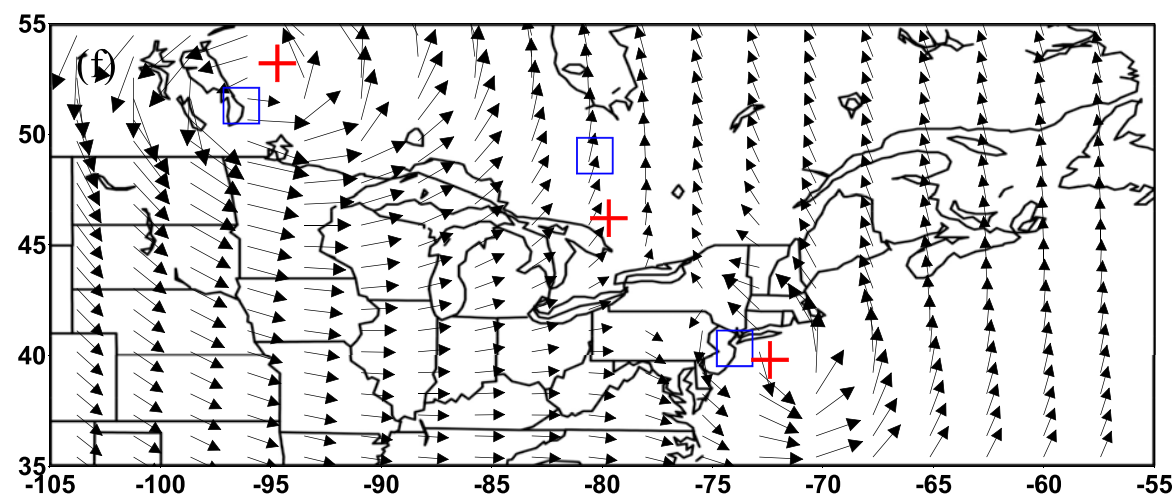

GEM min. and max. rotational and divergent velocity $(\mathrm{m} / \mathrm{s})$ at $500 \mathrm{hPa}$ induced by cyclones $A$ and $C$

$$
\overrightarrow{1.0} \underset{20.8}{\longrightarrow}
$$

FIG. 10. (Continued) 
Similarly, at 0300 UTC 24 July, the 500-hPa NARRanalyzed wind field (Fig. 6a), cyclone-induced fields (Figs. 6b,d-f), and environmental flows (Fig. 6c) demonstrate similar characteristics. For example, at $500 \mathrm{hPa}$, the cyclone $\mathrm{B}-, \mathrm{A}-$, and $\mathrm{C}-$-induced rotational flows dominate over their induced divergent flows (Figs. 6b,d,e). As expected, the cyclone B-induced divergent flow at $500 \mathrm{hPa}$ is much weaker than that at $1000 \mathrm{hPa}$ (cf. Figs. $4 \mathrm{~b}$ and $6 \mathrm{~b}$ ).

As displayed in Fig. 6c, the 500-hPa environmental flow is about $6 \mathrm{~m} \mathrm{~s}^{-1}$ northeastward at and around the center of cyclone $\mathrm{B}$, and its resulting advection is consistent with and can largely explain the northeastward movement of cyclone B from 0300 to 0600 UTC at $500 \mathrm{hPa}$ (denoted by blue squares in Fig. 1a).

At 0300 UTC, the cyclone A-induced rotational flow is about $6 \mathrm{~m} \mathrm{~s}^{-1}$ northeastward at and around the center of cyclone B at $500 \mathrm{hPa}$ (Fig. 6d), while the cyclone $\mathrm{C}$-induced rotational flow is $2 \mathrm{~m} \mathrm{~s}^{-1}$ southwestward (Fig. 6e). Thus, up to 0300 UTC, the cyclone A-induced flow still plays a dominant role in advecting the target cyclone $\mathrm{B}$ at $500 \mathrm{hPa}$. After cancellation of the cyclones $\mathrm{A}$ - and $\mathrm{C}$-induced flows, the net effect is that cyclone $\mathrm{A}$ has net velocity of $4 \mathrm{~m} \mathrm{~s}^{-1}$ to advect cyclone $\mathrm{B}$ northeastward (Fig. 6f), which contributes more than $67 \%$ of the environmental flow in advecting the cyclone $\mathrm{B}$ at $500 \mathrm{hPa}$.

\section{b. Diagnoses of cyclone-induced flows and their interactions in GEM}

Figure 7a shows the GEM wind field at $1000 \mathrm{hPa}$ at 0000 UTC 24 July, which is used to compute the target cyclone B-induced rotational and divergent flows (Fig. 7b). It is interesting to note that both rotational and divergent flows induced by cyclone B in the GEM are much weaker than their counterpart benchmark flows (Fig. 3b) computed from the NARR-analyzed wind field (Fig. 3a). In particular, the cyclone B-induced maximum divergent flow in the GEM is about $2 \mathrm{~m} \mathrm{~s}^{-1}$, whereas the cyclone B-induced divergent flow in the NARR is about $5 \mathrm{~m} \mathrm{~s}^{-1}$. This indicates that at $1000 \mathrm{hPa}$ at $0000 \mathrm{UTC}$, cyclone $\mathrm{B}$ in the GEM is not only displaced from the one in the NARR analysis (see Fig. 1) but also has much weaker divergent flow than the benchmark cyclone $B$ in the NARR analysis.

The environmental flow changes its direction around the center of cyclone B from mainly northward on the east side to southward on the west side. Thus, the environmental flow at the center of cyclone $\mathrm{B}$ is less than $1 \mathrm{~m} \mathrm{~s}^{-1}$ northward and its resulting advection can largely explain the very slow northward movement (about $20 \mathrm{~km}$ ) of cyclone B from 0000 to $0300 \mathrm{UTC}$ at $1000 \mathrm{hPa}$ (as shown by red plus signs in Fig. 1b). The cyclones A and $\mathrm{C}$-induced flows diminish more rapidly away from their centers at $1000 \mathrm{hPa}$ (Figs. $7 \mathrm{~d}, \mathrm{e}$ ), so the rotational and divergent flows induced by the two cyclones can be neglected near the center of cyclone B (Fig. 7f).

Figure 8a exhibits the GEM-forecast wind field at $1000 \mathrm{hPa}$ at 0300 UTC 24 July, from which the target cyclone $\mathrm{B}$-induced rotational and divergent flows are computed (Fig. 8b). At 0300 UTC, the cyclone Binduced rotational and divergent flows in the GEM become even weaker than those at 0000 UTC (cf. Figs. 7b and $8 \mathrm{~b}$ ). Also, at this time the GEM-forecast cyclone Binduced flows at $1000 \mathrm{hPa}$ become much weaker than the benchmark cyclone B in the NARR analysis (cf. Figs. 4b and $8 b$ ).

As shown in Fig. 8c, the environmental flow still changes its direction around the center of cyclone B from mainly northward on the east side to southward on the west side. Hence, the environmental flow at the center of cyclone $B$ is still just about $1 \mathrm{~m} \mathrm{~s}^{-1}$ northward and its resulting advection is consistent with the very slow northward movements of the center of cyclone B at $1000 \mathrm{hPa}$ from 0000 to $0300 \mathrm{UTC}$ and from 0300 to 0600 UTC (as shown by red plus signs in Fig. 1b). At the center of cyclone $\mathrm{B}$ at $1000 \mathrm{hPa}$, the flow induced by cyclone $\mathrm{A}$ is small (Fig. 8d), and the combined two cyclone-induced flows (Figs. $8 \mathrm{~d}, \mathrm{e}$ ) are about $1.5 \mathrm{~m} \mathrm{~s}^{-1}$ southwestward (Fig. 8f).

Figure 9a displays the GEM initial wind field at $500 \mathrm{hPa}$ at 0000 UTC $24 \mathrm{July}$, which is used to compute the rotational and divergent flows induced by the target cyclone B (Fig. 9b). As in the NARR, the induced divergent flow is much weaker and diminishes more rapidly away from the center of cyclone $\mathrm{B}$ than its induced rotational flow (cf. Figs. 5b and $9 \mathrm{~b}$ ). This is also true for the divergent flows induced by cyclone $\mathrm{C}$ of the two datasets (cf. Figs. 5e and $9 \mathrm{e}$ ). Again, the A- and C-induced rotational flows at $500 \mathrm{hPa}$ (Figs. 9d,e) are much stronger than those at $1000 \mathrm{hPa}$ (Figs. 7d,e).

As shown in Fig. 9c, the environmental flow is about $6 \mathrm{~m} \mathrm{~s}^{-1}$ northward at and around the center of cyclone B at $500 \mathrm{hPa}$, and its resulting advection can largely explain the slow northward movement (about of $120 \mathrm{~km}$ ) of cyclone B at $500 \mathrm{hPa}$ from 0000 to 0300 UTC (as shown by blue squares in Fig. 1b).

Near the center of cyclone B at $500 \mathrm{hPa}$, the cyclone A-induced rotational flow is about $5 \mathrm{~m} \mathrm{~s}^{-1}$ northeastward (Fig. 9d), while the cyclone $\mathrm{C}$-induced rotational flow is about $2 \mathrm{~m} \mathrm{~s}^{-1}$ southwestward (Fig. 9e). Thus, the cyclone A-induced flow plays a major role in advecting the target cyclone $\mathrm{B}$ at $500 \mathrm{hPa}$, as it is only fractionally offset by the C-induced flow at and around the center of cyclone B (Fig. 9f). 


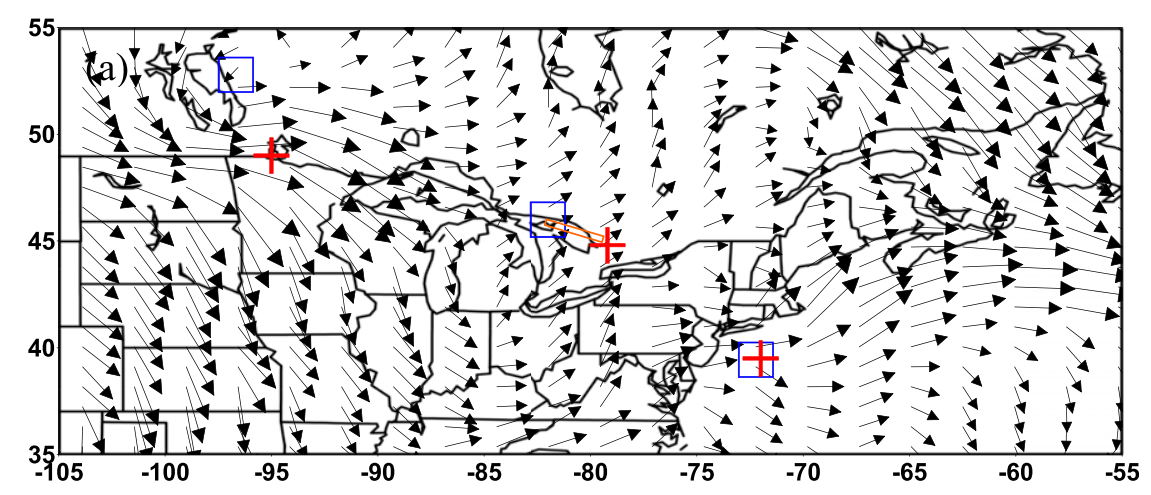

NARR enviornmental velocity $(\mathrm{m} / \mathrm{s})$ difference between $500 \mathrm{hPa}$ and $1000 \mathrm{hPa}$

$$
\overrightarrow{1.0} \underset{35.0}{\longrightarrow}
$$

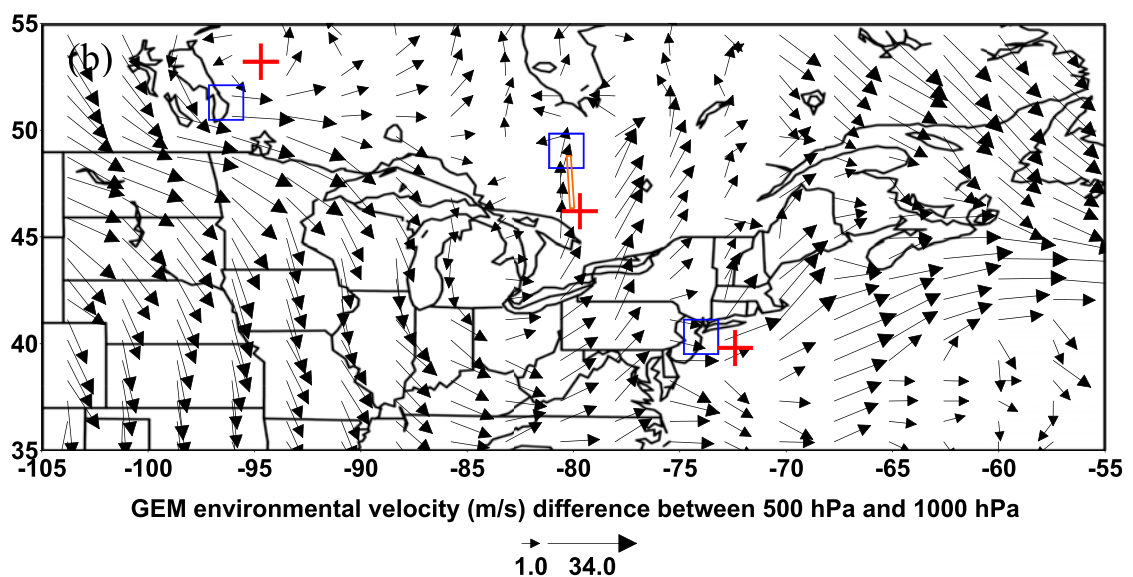

FIG. 11. (a) NARR and (b) the GEM model environmental velocity $\left(\mathrm{m} \mathrm{s}^{-1}\right)$ difference between 500 and $1000 \mathrm{hPa}$ at $0300 \mathrm{UTC} 24 \mathrm{Jul}$. The rectangle bar in orange color indicates the tilting direction of cyclone B from 1000 to $500 \mathrm{hPa}$. Plus signs and squares respectively denote the geographic locations for centers of 1000- and 500-hPa cyclones A, B, and C, from left to right.

The GEM-forecast 500-hPa wind field at 0300 UTC 24 July is presented in Fig. 10a, based on which the target cyclone B-induced rotational and divergent flows are computed. Like the diagnosed results at 0000 UTC, the cyclone B-induced divergent flow is much weaker and diminishes more rapidly away from its center than the induced rotational flow at $500 \mathrm{hPa}$ (Fig. 10b); this is similar for the divergent flows induced by cyclones $\mathrm{A}$ and C (Figs. 10d,e). At this time, the cyclone B-induced rotational flow at $500 \mathrm{hPa}$ (Fig. 10b) is still stronger than that at $1000 \mathrm{hPa}$ (Fig. 8b).

The environmental flow shown in Fig. 10c is still about $6 \mathrm{~m} \mathrm{~s}^{-1}$ northward near the center of cyclone $\mathrm{B}$ at $500 \mathrm{hPa}$, and once again its resulting advection is consistent with the slow northward movements of cyclone $\mathrm{B}$ at $500 \mathrm{hPa}$ from 0000 to $0300 \mathrm{UTC}$ and from 0300 to 0600 UTC (denoted by blue squares in Fig. 1b). Near the center of cyclone $\mathrm{B}$, the cyclone $\mathrm{A}$-induced rotational flow is still about $5 \mathrm{~m} \mathrm{~s}^{-1}$ northeastward (Fig. 10d) and the cyclone $\mathrm{C}$-induced rotational flow is $2 \mathrm{~m} \mathrm{~s}^{-1}$ southwestward (Fig. 10e), indicating that the cyclone A-induced flow is still dominant in advecting the target cyclone $\mathrm{B}$ at $500 \mathrm{hPa}$, since it is only fractionally offset by the $\mathrm{C}$-induced flow (Fig. 10f).

\section{c. Errors in cyclone locations and structures leading to the missed severe rainfall forecast}

As demonstrated in Fig. 11a, cyclone B in the NARR significantly tilts northwestward with a horizontal distance of about $340 \mathrm{~km}$ between the 1000 - and $500-\mathrm{hPa}$ cyclone centers at 0300 UTC. In contrast, cyclone B in the GEM model has little westward tilt (Fig. 11b). Furthermore, the observed cyclone B tilted northwestward with height has components against the vertical shear of the environmental flow between 500 and $1000 \mathrm{hPa}$, suggesting positive vorticity advection by thermal wind of the environmental flow (Fig. 11a). As explained earlier in the introduction section, this is conducive to 

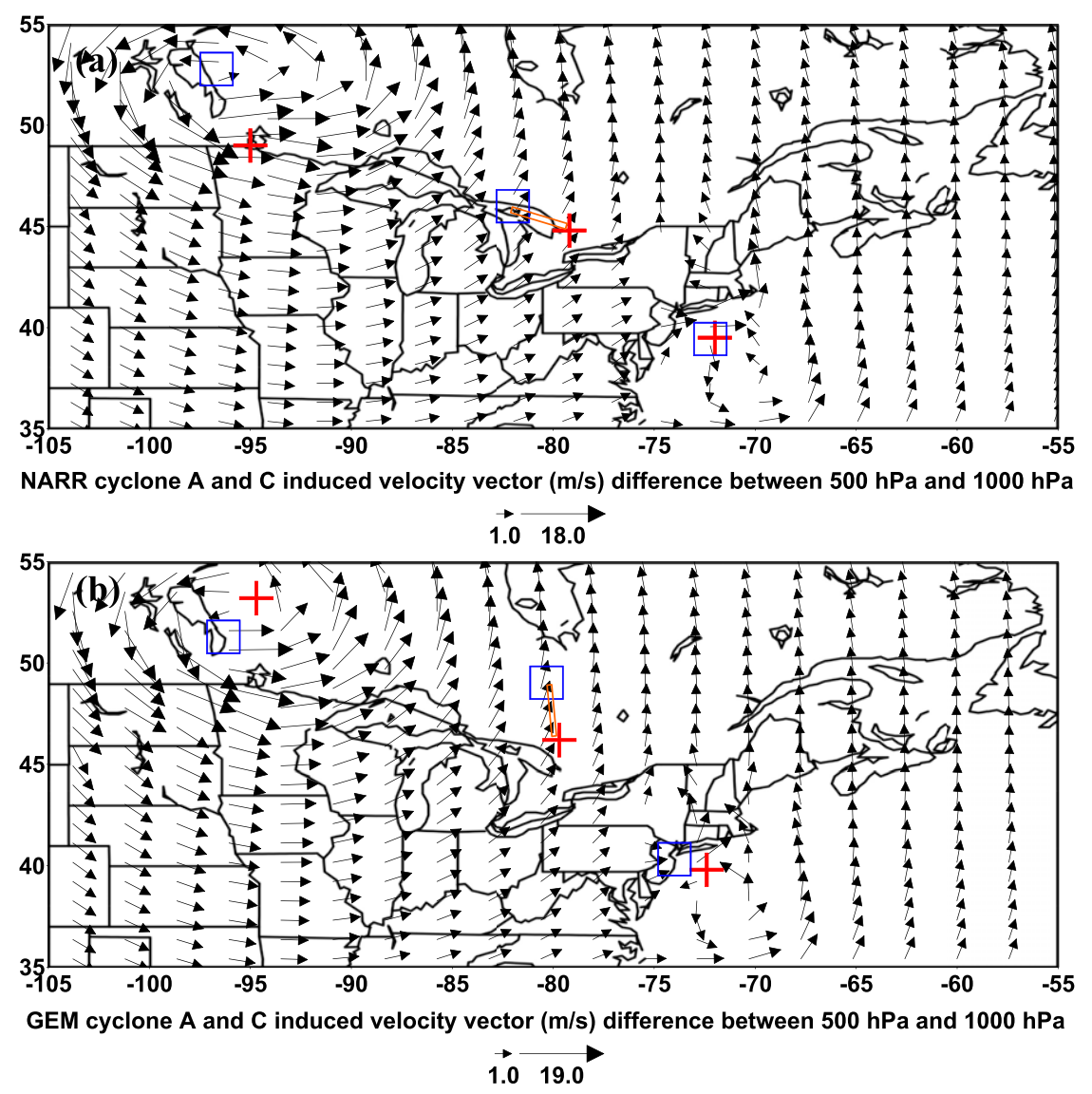

FIG. 12. As in Fig. 11, but for cyclones A and C-induced velocity vector $\left(\mathrm{m} \mathrm{s}^{-1}\right)$.

upward motion and favorable for cyclone B's intensification. On the other hand, the GEM-predicted cyclone B is tilted northward largely along the vertical shear of the environmental flow between 500 and $1000 \mathrm{hPa}$ (Fig. 11b). This suggests negative vorticity advection by thermal wind of the environmental flow, which was conducive to downward motion and unfavorable for cyclone B's intensification, resulting in the missed forecast of severe rainfall in Ottawa (Cao and Zhang 2016).

To understand the roles played by flows induced by cyclones $\mathrm{A}$ and $\mathrm{C}$, we compare the two cyclone-induced vertical shears to the vertical shear of the environmental flows at 0300 UTC. As shown in Fig. 12a, cyclone $\mathrm{B}$ in the NARR tilts northwestward with components against the $\mathrm{A}$ - and $\mathrm{C}$-induced vertical shear between 500 and $1000 \mathrm{hPa}$, which is similar to the vertical shear of environmental flows (Fig. 11a). The two cyclone-induced vertical shears contribute to strong cyclonic vorticity advection by thermal wind, leading to upward motion, and associated precipitation. In the GEM model, however, cyclone B tilts northward with height along the A- and C-induced vertical shear between 500 and $1000 \mathrm{hPa}$ (Fig. 12b), which is again similar to the vertical shear of environmental flows (Fig. 11b). Certainly, this structure is conducive to downward motion and unfavorable for producing precipitation.

To gain further insight into the roles played by cyclone B itself, we compute the residual flow by subtracting the cyclones $\mathrm{A}$ and $\mathrm{C}$-induced flows from the total flow. This residual flow contains the flow induced by cyclone $\mathrm{B}$ and the other remaining. In the neighborhood of the 500-hPa center of cyclone B, a strong cyclonic circulation of residual flows appears in the NARR between the 500- and the 1000-hPa centers of cyclone B (see the red circle in Fig. 13a), but it is not observed over the same region in the GEM model (Fig. 13b). This is consistent with the previously mentioned mechanism of positive vorticity advection by thermal wind according to the Sutcliffe development theory (Sutcliffe 1947; Trenberth 1978) that played an important role in cyclone B's development in the NARR but was absent in the GEM model.

At $1000 \mathrm{hPa}$ in the NARR, we have observed a strong convergence of residual flows around the center of 


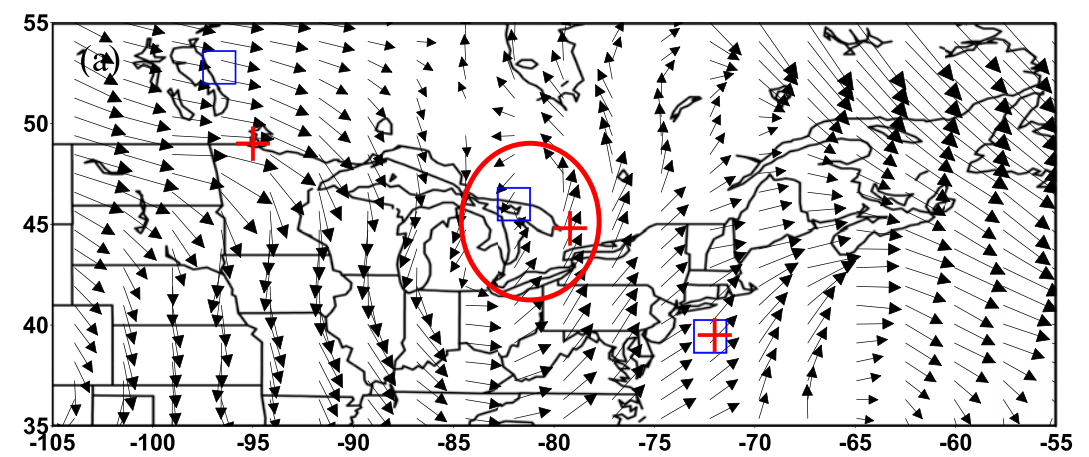

Min. and max. of vector $(\mathrm{m} / \mathrm{s})$ difference between NARR total and those induced by cyclones $A$ and $C$ $\overrightarrow{1.0} \underset{27.0}{\longrightarrow}$

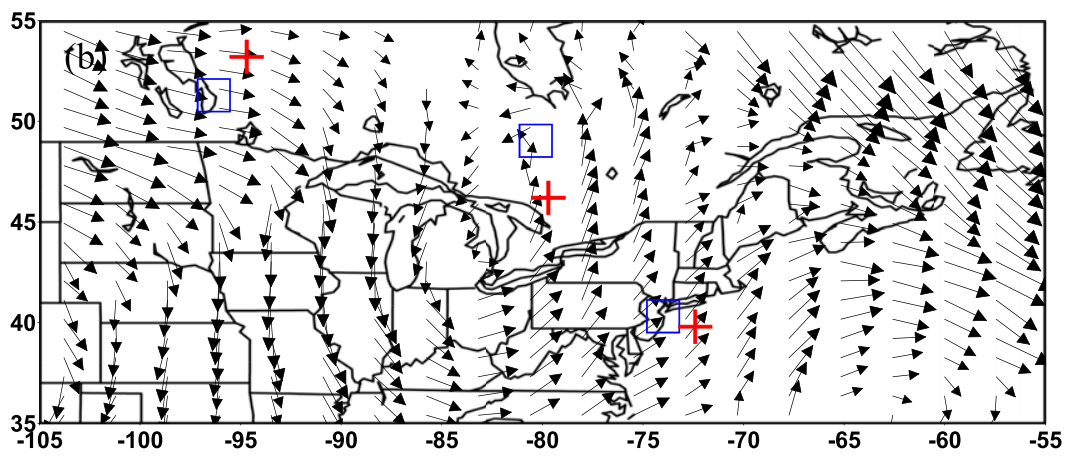

Min. and max. of vector $(\mathrm{m} / \mathrm{s})$ difference between NARR total and those induced by cyclones $A$ and $C$

$$
\overrightarrow{1.0} \underset{29.9}{\longrightarrow}
$$

FIG. 13. Horizontal velocity vectors obtained by (a) subtracting cyclones A and C induced from NARR analyzed and (b) subtracting cyclones A and C induced from the GEM forecast at $500 \mathrm{hPa}$ at 0300 UTC $24 \mathrm{Jul} 2009$. The red circle denotes a cyclonic circulation between 1000- and 500-hPa cyclone-B centers. Plus signs and squares respectively denote the geographic locations for centers of 1000- and 500-hPa cyclones A, B, and C, from left to right.

cyclone B, especially extending from its center southward, in addition to the cyclonic circulation around cyclone B (Fig. 14a). This convergence pattern is consistent with the cyclone $\mathrm{B}$-induced divergent flows at $1000 \mathrm{hPa}$ (Fig. 4b). However, such a convergence is not observed in the GEM model (Fig. 14b), which is consistent with near-zero cyclone $\mathrm{B}$-induced divergent flows (Fig. 8b). The abovementioned differences between the NARR and the GEM model are observed not only at 0300 UTC but also at 0000 and 0600 UTC (not shown).

We also compare the cyclone B-induced divergent flows at $1000 \mathrm{hPa}$ between the NARR and the GEM model in Fig. 15, showing that at and to the southeast of cyclone B's center the induced divergent velocity from 0000 UTC NARR is about $2.8 \mathrm{~m} \mathrm{~s}^{-1}$ northwestward pushing $\mathrm{B}$ toward the convergence zone to the northwest. On the other hand, the induced divergent velocity from the GEM model is about $1 \mathrm{~m} \mathrm{~s}^{-1}$ northeastward at and to the southeast of cyclone B's center, with no organized convergence zone. Similar differences occur at 0300 UTC (Figs. 15b,d).

\section{Discussion and conclusions}

In this work, we have developed a new diagnostic method to examine cyclone-cyclone interactions. Based on this method, the rotational and divergent flows induced by a cyclone are computed by inverting the vorticity and divergence in the vortex core area of the cyclone. Using this method, the influences on a target cyclone by its own and the other cyclone-induced fields can be evaluated appropriately in connection with the target cyclone's movement and associated precipitation. Furthermore, the influences of the environmental flows and residual flows on the target cyclone can be quantitatively assessed.

The new method improves the traditional point vortex model in the following aspects. 1) The new method provides a way to invert both vorticity and 


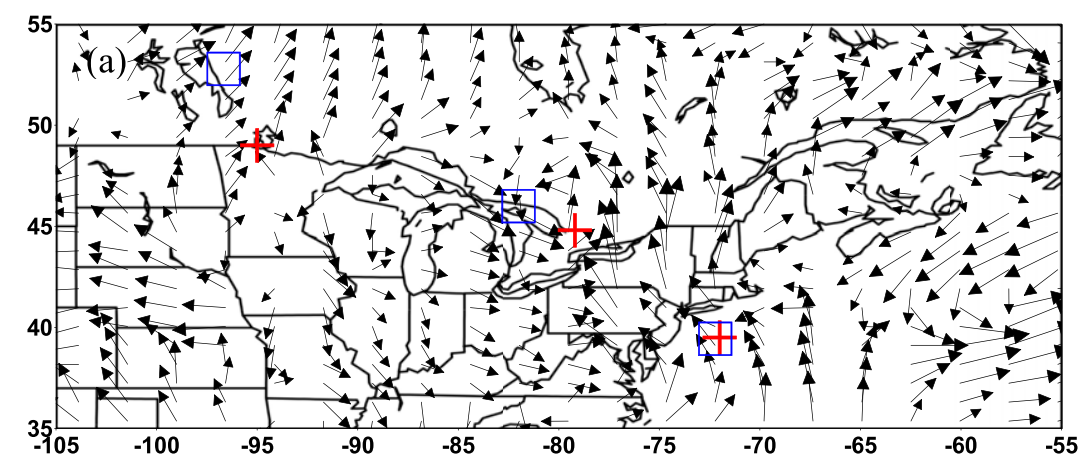

Min. and max. of vector $(\mathrm{m} / \mathrm{s})$ difference between NARR total and those induced by cyclones $A$ and $C$ $\overrightarrow{1.0} \overrightarrow{12.7}$

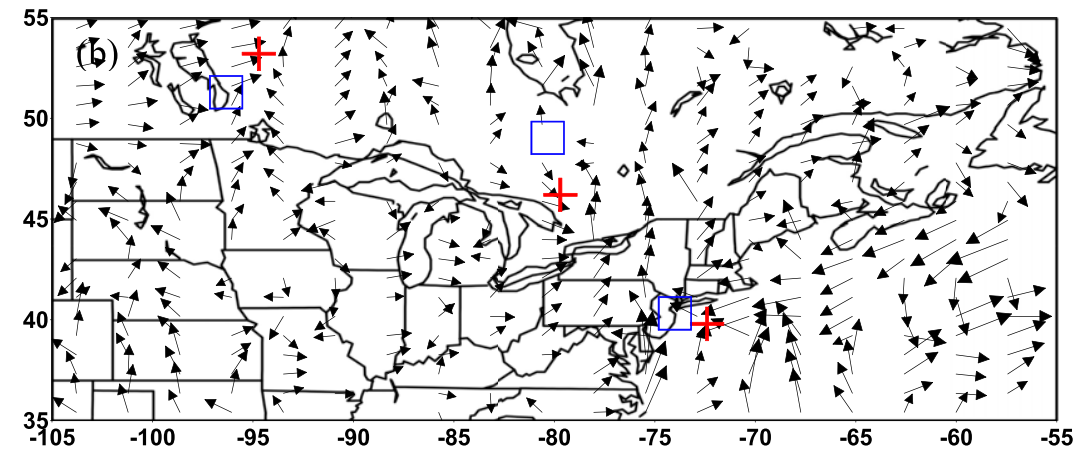

Min. and max. of vector $(\mathrm{m} / \mathrm{s})$ difference between GEM total and those induced by cyclones $A$ and $C$ $\overrightarrow{1.0} \underset{17.8}{\longrightarrow}$

FIG. 14. As in Fig. 13, but at $1000 \mathrm{hPa}$ at 0300 UTC 24 Jul 2009.

divergence in a well-defined vortex core area rather than at a point (see the procedure in Fig. 2). In the point vortex model, however, the vorticity that induces the velocity field is concentrated at a single point with infinite intensity, and the induced velocity increases boundlessly toward this point [see Eq. (1)]. This singularity is avoided in our new method. 2) The velocity induced by a point vortex is purely circular and becomes singular at the vortex center, which implies that the point vertex cannot be advected by its own induced velocity. However, in our model, the vortex core area is used to characterize and represent the cyclone, and in this area the relative vorticity and divergence-induced velocities can influence the cyclone center's movement unless their distributions are perfectly axisymmetric with respect to the cyclone center. 3) The new method provides the divergenceinduced velocity field that is absent in the point vortex model. This offers an opportunity to examine the effect of divergence-induced velocity on the target cyclone's movement. In our case, the movement of cyclone B's center at $1000 \mathrm{hPa}$ is partially influenced by the divergent velocity induced by cyclone $\mathrm{B}$ itself (see Fig. 15) but not much influenced by the cyclones A- and C-induced divergent velocities.

Our new method is employed in this study to examine a missed forecast of summer severe rainfall involving three cyclone-cyclone interactions. In this severe rainfall event, the target cyclone B predicted by the operational model is horizontally shifted to an unfavorable location as a result of inaccurate prediction of the interactions of the target cyclone $\mathrm{B}$ with the other two cyclones A and C. This leads to missed forecasts with large errors in precipitation location and intensity.

It is found that the A- and C-induced horizontal velocity fields and (residual) environmental flows act differently in influencing the movement of cyclone B prior to and during the severe rainfall period. Prior to the severe rainfall occurrence, in the NARR the residual environmental flows and cyclone B-induced flows (especially divergent flows) contributed to the northwestward movement of cyclone $\mathrm{B}$ at $1000 \mathrm{hPa}$ where the A- and C-induced flows were largely offset, whereas in the GEM model, the cyclones $\mathrm{A}$ and $\mathrm{C}$-induced horizontal velocities were small and the residual environmental flows as well as cyclone B-induced flows were 

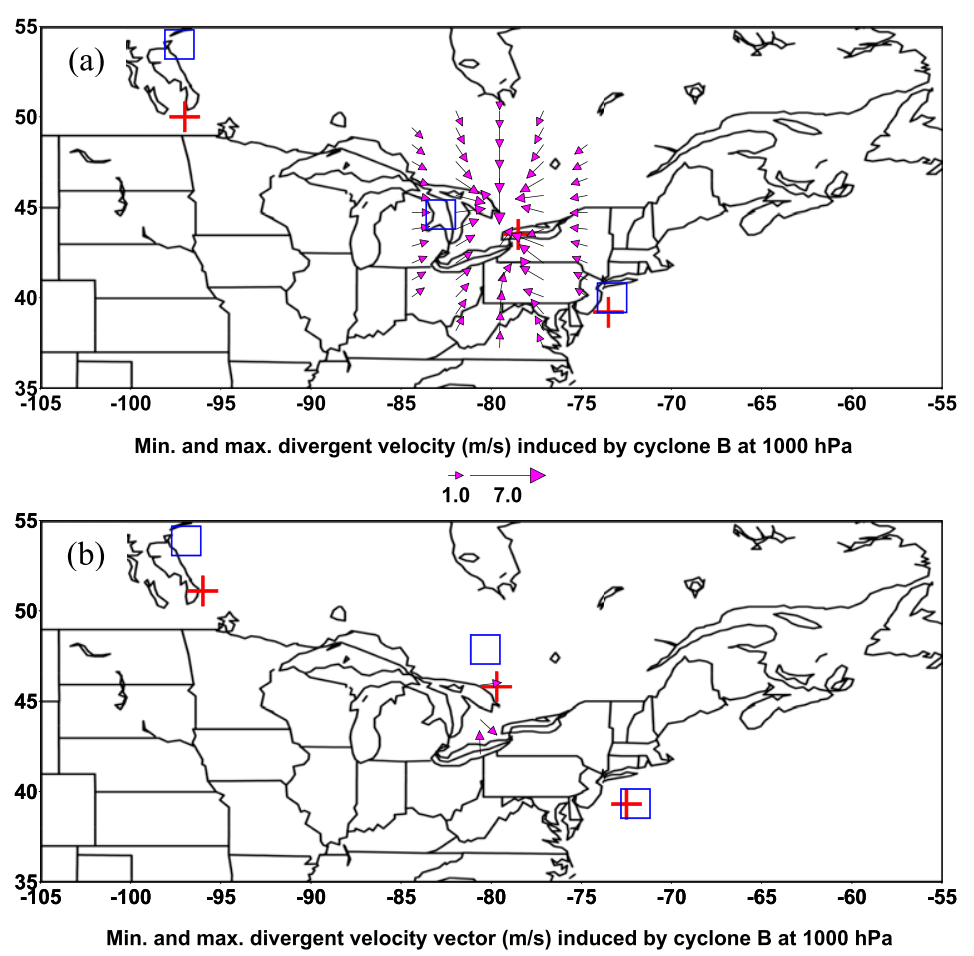

$$
\overrightarrow{1.0} \underset{6.0}{\longrightarrow}
$$

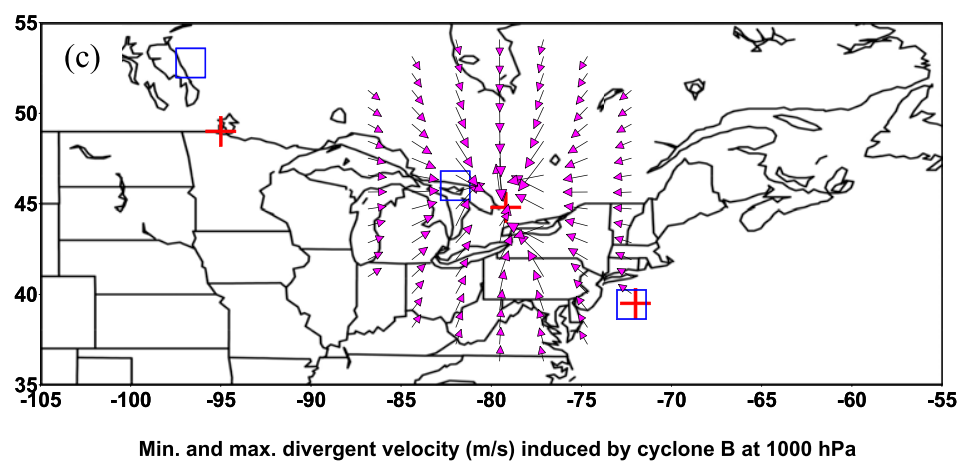

$$
\overrightarrow{1.0} \underset{6.2}{\longrightarrow}
$$

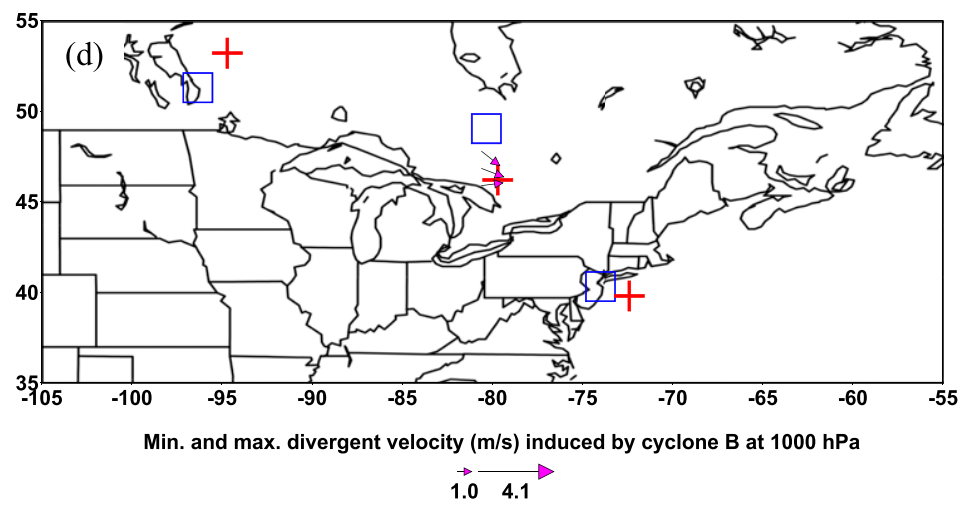

FIG. 15. Cyclone B-induced divergent flow ( $\mathrm{m} \mathrm{s}^{-1}$; purple) of (a),(c) NARR and (b),(d) GEM model at $1000 \mathrm{hPa}$ at (top) 0000 and (bottom) 0300 UTC 24 Jul 2009. Plus signs and squares respectively denote the geographic locations for centers of 1000- and 500-hPa cyclones A, B, and C, from left to right. 
also weak at $1000 \mathrm{hPa}$, resulting in slower movement of cyclone B than the observed. When severe rainfall occurred, in the NARR the large residual environmental velocity assisted the cyclone B's northwestward movement at $1000 \mathrm{hPa}$, but in the GEM model cyclone B remained stalled. Furthermore, prior to and during the severe rainfall period, the residual flows at $1000 \mathrm{hPa}$ in the NARR revealed the development of a convergence line around cyclone B that mainly extended from its center southward, but this feature was absent in the GEM model. At the same time, cyclone B in the NARR tilted northwestward with height partially against the vertical shear of environmental flow (mainly contributed by the A- and C-induced flows) between 500 and $1000 \mathrm{hPa}$. This indicates that the A- and C-induced shears promote positive vorticity advection by thermal winds, which are favorable for upward motion, cyclone intensification, and associated precipitation. On the other hand, cyclone B in the GEM model has a northward tilt along the $\mathrm{A}$ - and $\mathrm{C}$-induced vertical shears between 500 and $1000 \mathrm{hPa}$, indicating negative vorticity advection by thermal winds, which is favorable for downward motion and detrimental to precipitation development.

Cyclone B's northwestward tilt with height against the vertical shear of environmental flow may be envisioned as an up-shear-tilted PV anomalies. This up-shear-tilted PV anomaly structure could lead to cyclone intensification via reinforced interactions between the upper-level and lower-level PV anomalies (see section 6e and Fig. 21 of Hoskins et al. 1985). The above-envisioned intensification for cyclone $\mathrm{B}$ requires further detailed investigations on PV anomaly interactions, beyond the scope of this paper, perhaps by following and extending previous studies (e.g., Davis and Emanuel 1991; Davis 1992; Davis et al. 1993; Stoelinga 1996; Huo et al. 1999; Wang and Zhang 2003; Kieu and Zhang 2010; Breeden and Martin 2018). To this end, the semibalanced model of $\mathrm{Xu}$ (1994) in pseudoheight (essentially pressure) coordinates or $\mathrm{Xu}$ and $\mathrm{Cao}$ (2012) in terrain-following pressure coordinates can be particularly useful because it was derived more concisely and selfconsistently than the truncated model systems derived and/or used in previous studies of PV anomaly interactions.

With the framework established in this study, we may expect that the current work can be easily applied to evaluating more cases of cyclone-cyclone interactions over land as well as over tropical oceans, such as tropical cyclones, because these cyclones often cause catastrophic damage and impacts to our life, property, and society. The new diagnostic method developed in this study may also be used routinely to decompose model-forecast cyclone- or vortex-induced flows and thus to detect and resolve potential problems such as cyclone interaction and/or steering in the model forecasts in advance.

Acknowledgments. We thank Drs. Victor Chung and Junhua Zhang for carefully reading an earlier version of the paper and providing constructive suggestions and Dr. William Burrows for his constructive comments on part of the earlier version of paper. We appreciate Dr. Lin Zhu's assistance in obtaining the NARR digital data. We also appreciate three anonymous reviewers for their constructive suggestions and comments to improve the quality of the paper. The operational GEM regional model forecast data were obtained from the Canadian Meteorological Centre. NCEP reanalysis data were provided by the NOAA/OAR/ESRL PSD (http://www.esrl.noaa.gov/ $\mathrm{psd} /$ ). The observed surface precipitation data and radar data were obtained from the Data Analysis and Archive Division of Environment and Climate Change Canada. The atmospheric soundings were obtained from the University of Wyoming.

\section{REFERENCES}

Aref, H., 1983: Vortex motion. Annu. Rev. Fluid Mech., 11, 95-122. Batchelor, G. K., 1980: An Introduction to Fluid Dynamics. 5th ed. Cambridge University Press, 615 pp.

Breeden, M., and J. E. Martin, 2018: Analysis of the initiation of an extreme North Pacific jet retraction using piecewise tendency diagnosis. Quart. J. Roy. Meteor. Soc., 144, 1895-1913, https:// doi.org/10.1002/qj.3388.

Cao, J., and Q. Xu, 2011: Computing streamfunction and velocity potential in a limited domain of arbitrary shape. Part II: Numerical methods and test experiments. Adv. Atmos. Sci., 28, 1445-1458, https://doi.org/10.1007/s00376-011-0186-5.

Cao, Z., 2008: Severe hail frequency over Ontario, Canada: Recent trend and variability. Geophys. Res. Lett., 35, L14803, https:// doi.org/10.1029/2008GL034888.

— , and D.-L. Zhang, 2004: Track surface cyclones with moist potential vorticity. Adv. Atmos. Sci., 21, 830-835, https:// doi.org/10.1007/BF02916379.

_ variability over Ontario, Canada. J. Appl. Meteor. Climatol., 48, 1955-1960, https://doi.org/10.1175/2009JAMC2055.1.

—, and D.-L. Zhang, 2016: Analysis of missed summer severe rainfall forecasts. Wea. Forecasting, 31, 433-450, https:// doi.org/10.1175/WAF-D-15-0119.1.

- P. Pellerin, and H. Ritchie, 2004: Verification of mesoscale modeling for the severe rainfall event over southern Ontario in May 2000. Geophys. Res. Lett., 31, L23108, https://doi.org/ 10.1029/2004GL020547.

Chan, J. C. L., and W. M. Gray, 1982: Tropical cyclone movement and surrounding flow relationships. Mon. Wea. Rev., 110, 1354-1374, https://doi.org/10.1175/1520-0493(1982)110<1354: TCMASF $>2.0 . \mathrm{CO} ; 2$. 
and S. Q. Kidder, 1980: Forecasting tropical cyclone turning motion from surrounding wind and temperature fields. Mon. Wea. Rev., 108, 778-792, https://doi.org/10.1175/ 1520-0493(1980)108<0778:FTCTMF>2.0.CO;2.

Côté, J., S. Gravel, A. Méthot, A. Patoine, M. Roch, and A. Staniforth, 1998: The operational CMC-MRB Global Environmental Multiscale (GEM) model. Part I: Design considerations and formulation. Mon. Wea. Rev., 126, 1373-1395, https://doi.org/10.1175/ 1520-0493(1998)126<1373:TOCMGE > 2.0.CO;2.

Davis, C. A., 1992: Piecewise potential vorticity inversion. J. Atmos. Sci., 49, 1397-1411, https://doi.org/10.1175/ 1520-0469(1992)049<1397:PPVI>2.0.CO;2.

_ , and K. A. Emanuel, 1991: Potential vorticity diagnostics of cyclogenesis. Mon. Wea. Rev., 119, 1929-1953, https://doi.org/ 10.1175/1520-0493(1991)119<1929:PVDOC > 2.0.CO;2.

—, M. T. Stoelinga, and Y.-H. Kuo, 1993: The integrated effect of condensation in numerical simulations of extratropical cyclogenesis. Mon. Wea. Rev., 121, 2309-2330, https://doi.org/ 10.1175/1520-0493(1993)121<2309:TIEOCI >2.0.CO;2.

Fujiwhara, S., 1931: Short note on the behavior of two vortices. Proc. Phys. Math. Soc. Japan. Ser. 3, 13, 106-110.

Hoskins, B. J., M. E. McIntyre, and A. W. Robertson, 1985: On the use and significance of isentropic potential vorticity. Quart. J. Roy. Meteor. Soc., 111, 877-946, https://doi.org/ 10.1002/qj.49711147002.

Huo, Z., D.-L. Zhang, and J. Gyakum, 1999: The interaction of potential vorticity anomalies in extratropical cyclogenesis. Part I: Static piecewise inversion. Mon. Wea. Rev., 127, 2546-2561, https://doi.org/10.1175/1520-0493(1999) 127<2546:IOPVAI $>2.0 . \mathrm{CO} ; 2$.

Kieu, C. Q., and D.-L. Zhang, 2010: A piecewise potential vorticity inversion algorithm and its application to hurricane inner-core anomalies. J. Atmos. Sci., 67, 2616-2631, https://doi.org/10.1175/ 2010JAS3421.1.

Lamb, H., 1945: Hydrodynamics. 6th ed. Dover Publications, 738 pp.
Mesinger, F., and Coauthors, 2006: North American Regional Reanalysis. Bull. Amer. Meteor. Soc., 87, 343-360, https:// doi.org/10.1175/BAMS-87-3-343.

Stoelinga, M. T., 1996: A potential vorticity-based study on the role of diabatic heating and friction in a numerically simulated baroclinic cyclone. Mon. Wea. Rev., 124, 849-874, https://doi.org/10.1175/ 1520-0493(1996)124<0849:APVBSO > 2.0.CO;2.

Sutcliffe, R. C., 1947: A contribution to the problem of development. Quart. J. Roy. Meteor. Soc., 73, 370-383, https:// doi.org/10.1002/qj.49707331710.

Trenberth, K. E., 1978: On the interpretation of the diagnostic quasi-geostrophic omega equation. Mon. Wea. Rev., 106, 131-137, https://doi.org/10.1175/1520-0493(1978)106<0131: OTIOTD $>2.0 . \mathrm{CO} ; 2$.

Wang, X., and D.-L. Zhang, 2003: Potential vorticity diagnosis of a simulated hurricane. Part I: Formulation and quasibalanced flow. J. Atmos. Sci., 60, 1593-1607, https://doi.org/ 10.1175/2999.1.

Xu, Q., 1994: Semi-balance model-Connection between geostrophic-type and balanced-type intermediate models. J. Atmos. Sci., 51, 953-970, https://doi.org/10.1175/15200469(1994)051<0953:SMBGTA > 2.0.CO;2.

— , and J. Cao, 2012: Semibalance model in terrain-following coordinates. J. Atmos. Sci., 69, 2201-2206, https://doi.org/ 10.1175/JAS-D-12-012.1.

,-- and S. T. Gao, 2011: Computing streamfunction and velocity potential in a limited domain of arbitrary shape. Part I: Theory and integral formulae. Adv. Atmos. Sci., 28, 14331444, https://doi.org/10.1007/s00376-011-0185-6.

Ziv, B., and P. Alpert, 1995: Rotation of binary cyclones-A data analysis study. J. Atmos. Sci., 52, 1357-1369, https://doi.org/ 10.1175/1520-0469(1995)052<1357:ROBCDA > 2.0.CO;2. , and — - 2003: Rotation of mid-latitude binary cyclones: A potential vorticity approach. Theor. Appl. Climatol., 76, 189-202, https://doi.org/10.1007/s00704-003-0011-x. 